\title{
HBeAg mediates inflammatory functions of macrophages by TLR2 contributing to hepatic fibrosis
}

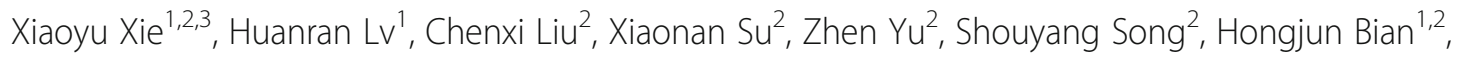
Miaomiao Tian ${ }^{1,3}$, Chengyong Qin ${ }^{1,2,3}$, Jianni Qi ${ }^{1,2,3^{*}}$ and Qiang Zhu ${ }^{1,2,3,4^{*}}$

\begin{abstract}
Background: We and others have confirmed activation of macrophages plays a critical role in liver injury and fibrogenesis during HBV infection. And we have also proved HBeAg can obviously induce the production of macrophage inflammatory cytokines compared with HBsAg and HBcAg. However, the receptor and functional domain of HBeAg in macrophage activation and its effects and mechanisms on hepatic fibrosis remain elusive.

Methods: The potentially direct binding receptors of HBeAg were screened and verified by Co-IP assay. Meanwhile, the function domain and accessible peptides of HBeAg for macrophage activation were analyzed by prediction of surface accessible peptide, construction, and synthesis of truncated fragments. Furthermore, effects and mechanisms of the activation of hepatic stellate cells induced by HBeAg-treated macrophages were investigated by Transwell, CCK-8, Gel contraction assay, Phospho Explorer antibody microarray, and Luminex assay. Finally, the effect of HBeAg in hepatic inflammation and fibrosis was evaluated in both human and murine tissues by immunohistochemistry, immunofluorescence, ELISA, and detection of liver enzymes.
\end{abstract}

Results: Herein, we verified TLR-2 was the direct binding receptor of HBeAg. Meanwhile, C-terminal peptide (122-143 aa.) of core domain in HBeAg was critical for macrophage activation. But arginine-rich domain of HBCAg hided this function, although $\mathrm{HBCAg}$ and $\mathrm{HBeAg}$ shared the same core domain. Furthermore, HBeAg promoted the proliferation, motility, and contraction of hepatic stellate cells (HSCS) in a macrophage-dependent manner, but not alone. PI3K-AKTmTOR and p38 MAPK signaling pathway were responsible for motility phenotype of HSCs, while the Smad-dependent TGF- $\beta$ signaling pathway for proliferation and contraction of them. Additionally, multiple chemokines and cytokines, such as CCL2, CCL5, CXCL10, and TNF-a, might be key mediators of HSC activation. Consistently, HBeAg induced transient inflammation response and promoted early fibrogenesis via TLR-2 in mice. Finally, clinical investigations suggested that the level of HBeAg is associated with inflammation and fibrosis degrees in patients infected with HBV.

Conclusions: HBeAg activated macrophages via the TLR-2/NF-KB signal pathway and further exacerbated hepatic fibrosis by facilitating motility, proliferation, and contraction of HSCs with the help of macrophages.

Keywords: HBeAg, Macrophage, Hepatic stellate cell, Inflammation, Fibrosis

\footnotetext{
*Correspondence: slaijn@126.com; zhuqiang@sdu.edu.cn

'Shandong Provincial Hospital Affiliated to Shandong First Medical University, Jinan, Shandong 250021, People's Republic of China

Full list of author information is available at the end of the article
}

(C) The Author(s). 2021 Open Access This article is licensed under a Creative Commons Attribution 4.0 International License, which permits use, sharing, adaptation, distribution and reproduction in any medium or format, as long as you give appropriate credit to the original author(s) and the source, provide a link to the Creative Commons licence, and indicate if changes were made. The images or other third party material in this article are included in the article's Creative Commons licence, unless indicated otherwise in a credit line to the material. If material is not included in the article's Creative Commons licence and your intended use is not permitted by statutory regulation or exceeds the permitted use, you will need to obtain permission directly from the copyright holder. To view a copy of this licence, visit http://creativecommons.org/licenses/by/4.0/. The Creative Commons Public Domain Dedication waiver (http://creativecommons.org/publicdomain/zero/1.0/) applies to the data made available in this article, unless otherwise stated in a credit line to the data. 


\section{Background}

Hepatitis B is a global public health problem, since patients infected with hepatitis B viruses (HBV) are at increased risk of progression to chronic active hepatitis, cirrhosis, and hepatocellular carcinoma (HCC) [1, 2]. After HBV entry into hepatocytes and begin to replicate, virus-related proteins can be detected in the liver and peripheral blood. HBV-related proteins are mainly composed of hepatitis B surface antigen ( $\mathrm{HBsAg}$ ), hepatitis B core-related antigen ( $\mathrm{HBcrAg}$ ), and $\mathrm{HBx}$ proteins [3]. HBcrAg consists of three proteins coded by the precore/ core region including hepatitis $B$ core antigen ( $\mathrm{HBcAg}$ ), hepatitis $\mathrm{B}$ e antigen ( $\mathrm{HBeAg}$ ), and a $22-\mathrm{kDa}$ precore protein. In clinical practice, $\mathrm{HBs} A g$ has been estimated as a surrogate marker of HBV infection or intrahepatic viral replicative activity. Several studies reveal that HBsAg plays a vital role in promoting persistent $\mathrm{HBV}$ infection, whereas others indicate $\mathrm{HBsAg}$ and $\mathrm{HBcAg}$ can also induce immune response and facilitate liver injury [3-5]. HBx proteins can sensitize hepatocytes to carcinogenic factors and lead to $\mathrm{HCC}$ by deregulating cell apoptosis and proliferation control [6]. Moreover, the level of serum HBeAg is associated with viral replication, infectivity, inflammation, severity of disease, and response to antiviral therapy [7]. However, the function of virus-related proteins to regulate the immune response and the underlying mechanisms have not been completely elucidated.

The persistence, clearance, and pathogenesis of HBV are closely related to the interaction between the innate immune system and various viral proteins. Macrophages, as an important component of the innate immune system, play a crucial role in detecting $\mathrm{HBV}$ and regulating inflammation-induced liver injury. Inflammatory cytokines from macrophages inhibit virus replication, but also result in damage of hepatocytes simultaneously [8]. On the other hand, viral proteins abrogate immune responses of macrophages leading to immune tolerance or establishment of chronic HBV infection [9]. Our recent work has proved that, compared with $\mathrm{HBcAg}$ and HBsAg, HBeAg is the most important element in HBVassociated antigens inducing macrophage activation, and HBeAg-induced miR-155 accelerate liver injury by promoting inflammatory cytokine production [10]. Yet, the receptors by which macrophages recognize $\mathrm{HBeAg}$ and the molecular mechanism of their activation are still a mystery.

Toll-like receptor (TLR) family is one of the bestknown pattern recognition receptor (PRR) families and responsible for recognizing diverse molecules derived from pathogens and damaged host cells [11]. For example, lipoproteins and lipopolysaccharides, the major components of the outer membrane of bacteria, are the best-known ligands for TLR-2 and TLR-4. Moreover, intracellular life-encoding molecules, such as DNA and RNA, are recognized by TLR- 9 and TLR-3/7/8, respectively. Recently, TLR ligands are still increasing in number and cover a variety of microbial components. Chang et al. find TLR-2 may also play a key role in recognizing hepatitis C virus core and NS3 proteins, thereby activating macrophages [12]. Besides, Enterovirus-71 virus-like particles induce the activation and maturation of human monocyte-derived dendritic cells by activating TLR-4 [13]. Whether HBeAg could also be recognized by macrophages through TLR-dependent signal pathway remains to be further explored.

In chronic HBV infection, progressive hepatocellular damage induced by persistent immune response, accompany with extensive tissue remodeling and vascular disorganization, will ultimately culminate into fibrosis and cirrhosis [14]. It is well-known that activated hepatic stellate cells (HSCs) remain central effector cells driving its progression, which undergo a phenotypic transdifferentiation into highly proliferative, contractile, chemotactic, and fibrogenic myofibroblasts [15]. In hepatic microenvironment, extracellular signals from the surrounding cells can act in a paracrine manner to promote the activation of HSCs. Macrophages are one of the major regulators of fibrosis progression and remodeling of deposited extracellular matrix (ECM). Accumulating evidence indicates that activated macrophages can produce pro-fibrotic mediators, such as growth factors, cytokines, and chemokines, etc, contributing to the activation and recruitment of HSCs, and further accelerate the deposition of ECM. On the other hand, activated HSCs also secrete chemokines to attract macrophages, leading to the amplification of this pathological process [16]. Our previous results have established that macrophages activated by $\mathrm{HBeAg}$ increase the expression and secretion of multiple cytokines [10]. However, it is still unclear whether HBeAg can activate HSCs to promote the occurrence and progression of hepatic fibrosis directly or in a macrophage-dependent manner.

In this study, we uncovered that HBeAg affected the expression of TLRs in macrophages, thereby regulating the innate immune response. In accordance with the high expression of TLR-2, HBeAg acted as a new ligand of TLR-2 to induce growth factors, cytokines, and chemokines via NF$\kappa \mathrm{B}$-mediated signaling pathway, and its $\mathrm{C}$-terminal peptide (122-143 aa.) is critical for the activation of macrophages. In addition, we found that HBeAg promoted the proliferation, contraction, and motility of HSCs in a macrophagedependent manner, demonstrating a novel mechanism for the progression of hepatic fibrosis and its related complications. Consistent with the above-mentioned results, clinical data indicated the level of HBeAg is associated with grades of inflammation, macrophage infiltration, and the stage of fibrosis in patients infected with HBV. 


\section{Methods}

\section{Patients}

Two hundred twelve patients, including 61 subjects with acute hepatitis $\mathrm{B}$ (AHB) and 151 subjects with chronic hepatitis $\mathrm{B}(\mathrm{CHB})$, were recruited from Shandong Provincial Hospital Affiliated to Shandong First Medical University from May 2017 to March 2018. AHB and CHB were diagnosed based on EASL 2017 clinical practice guidelines on the management of hepatitis B virus infection [17]. The inclusion criteria for this study were (1) $\geq 18$ years old and (2) the presence of hepatitis B surface antigen. The exclusion criteria were (1) co-infection with HCV, HIV, or other chronic liver diseases; (2) a mean daily consumption of $>40 \mathrm{~g}$ of alcohol for men and $>20 \mathrm{~g}$ of alcohol for women; (3) previous liver surgery or liver transplantation; and (4) antiviral therapy or immunosuppressive drugs within 3 months. Verbal or written informed consents were obtained from each of the patients/guardians before being included in this study, and this study was approved by the Ethics Committee of Shandong Provincial Hospital Affiliated to Shandong First Medical University. Basic information of patients is summarized in Table 1. Additionally, complications of hepatic fibrosis and cirrhosis were detected by proficient endoscopists and ultrasound experts respectively [18].

\section{Animal experiments}

Male Balb/c mice were purchased from Beijing Vital River Laboratory Animal Technology Co., Ltd. (Beijing, China) and housed in a specific pathogen-free environment. All experiments were conducted with mice between 6 and 8 weeks of age in compliance with the Scientific Investigation Board of the Shandong Provincial Hospital Affiliated to Shandong First Medical University. To examine the role of $\mathrm{HBeAg}$ in vivo, mice (5 mice in each group) were injected with recombinant $\mathrm{HBeAg}$ $40 \mu \mathrm{g}$ or received the equivalent volume of PBS via tail vein, then were sacrificed at $4,8,12$, and $24 \mathrm{~h}$ respectively. To study the effect of HBeAg in the progress of hepatic fibrosis, mice were treated with a single intraperitoneal injection of olive oil or $\mathrm{CCl}_{4}(1 \mathrm{ml} / \mathrm{kg}$ in olive oil) at day 1 . At day 2 and day $3, \mathrm{CCl}_{4}$-treated mice received intravenous administration of $\mathrm{HBeAg} 40 \mu \mathrm{g}$ or the same volume of PBS ( $n=5$ per group). At day 4 , all mice were sacrificed, and the liver and blood were harvested and frozen for further analyses. Monocyte depletion was achieved by way of intraperitoneal injection of $200 \mu \mathrm{l}$ clodronate-liposome or control-liposome before $\mathrm{CCl}_{4}$ or HBeAg treatment. To validate the effect of TLR-2 in vivo, C29 was dissolved and diluted to appropriate doses, then injected intraperitoneally $(1.3 \mu \mathrm{mol} / \mathrm{g}) 1 \mathrm{~h}$ before $\mathrm{HBeAg}$ treatment, with the same volume of

Table 1 Clinical characteristics of enrolled subjects

\begin{tabular}{|c|c|c|c|}
\hline Variable & $\mathrm{CHB}(n=151)$ & $\mathrm{AHB}(n=61)$ & $P$ \\
\hline Age (years) & $54.41 \pm 9.69$ & $36.54 \pm 11.79$ & $<0.001$ \\
\hline Sex (male) & $121(80.10 \%)$ & $45(73.80 \%)$ & 0.309 \\
\hline $\mathrm{ALT}(\mathrm{IU} / \mathrm{L})$ & $36.00(25.00,49.00)$ & $1325.00(774.70,2345.50)$ & $<0.001$ \\
\hline AST (IU/L) & $32.00(20.00,50.00)$ & $897.00(375.00,1351.50)$ & $<0.001$ \\
\hline HBeAg (COI) & $0.14(0.11,1.20)$ & $20.03(5.85,148.88)$ & $<0.001$ \\
\hline $\mathrm{HBsAg}(\mathrm{COI})$ & $5611.50(879.15,6902.00)$ & $3666.61(1381.50,5918.0)$ & 0.426 \\
\hline HBV DNA $\left(\log _{10} 1 \mathrm{U} / \mathrm{mL}\right)$ & $3.27 \pm 1.83$ & $4.61 \pm 1.34$ & $<0.001$ \\
\hline Stage of fibrosis & & NS & NS \\
\hline 0 & $13(8.61 \%)$ & & \\
\hline 1 & $14(9.27 \%)$ & & \\
\hline 2 & $44(29.14 \%)$ & & \\
\hline 3 & $20(13.25 \%)$ & & \\
\hline 4 & $60(39.73 \%)$ & & \\
\hline Grade of inflammation & & NS & NS \\
\hline 0 & $10(6.62 \%)$ & & \\
\hline 1 & $92(60.93 \%)$ & & \\
\hline 2 & $29(19.21 \%)$ & & \\
\hline 3 & $20(13.25 \%)$ & & \\
\hline
\end{tabular}

Data are reported as mean \pm SD, median (interquartile range), or $n$ (\%)

Abbreviations: IU international units; $C O I$ cut-off index; $L S$ liver stiffness; $A L T$ alanine aminotransferase; $A S T$ aspartate aminotransferase; $H B e A g$ hepatitis B e antigen; $H B s A g$ hepatitis B surface antigen; HBV DNA hepatitis B DNA quantification 
dissolving reagent (10\% DMSO/40\% PEG300/5\% Tween$80 / 45 \%$ saline) as the vehicle group.

\section{Cell culture, reagents, and antibodies}

Mouse macrophage cell lines RAW264.7 (ATCC, Rockville, MD, USA) and human stellate cell lines LX-2 (Procell, Wuhan, China) were cultured in DMEM (GibcoBRL, Grand Island, NY, USA) containing 10\% (vol/vol) FBS (Gibco ${ }^{\circ}$ Sera, AUS). Human monocyte cell lines THP-1, U937 (ATCC, Rockville, MD, USA) were cultured in RPMI 1640 medium (Gibco; Thermo Fisher Scientific, Inc.) supplemented with $10 \% \mathrm{FBS}$ (Gibco ${ }^{\circ}$ Sera, AUS). Mouse primary hepatic stellate cells and Kupffer cells were obtained and cultured based on the previous description [4, 19]. Human monocyte-derived macrophages (hMDM) were differentiated from peripheral blood mononuclear cells (PBMCs) of healthy human blood donors using Ficoll-Paque density gradient centrifugation [12]. All cells were incubated at $37^{\circ} \mathrm{C}$ in an incubator with $5 \% \mathrm{CO}_{2}$.

HBeAg (ab91273) and HBcAg (ab119441) were purchased from Abcam (Abcam, Cambridge, UK). C29 (TLR-2 inhibitor, HY-100461), resatorvid (TLR-4 inhibitor, HY-11109), hydroxychloroquine sulfate (TLR-7/9 inhibitor, HY-B1370), CU-CPT9b (TLR-8 inhibitor, HY-112051), SB202190 (p38 MAPK inhibitor, HY-10295), SP600125 (JNK inhibitor, HY12041), PD98059 (ERK1/2 inhibitor, HY-12028), tofacitinib (JAK1/2/3 inhibitor, HY-40354), (E)-SIS3 (Smad3 inhibitor, HY-13013), and dactolisib (PI3K/mTOR inhibitor, HY50673) were acquired from MCE (MedChemExpress, Pudong New Area, Shanghai, China). PMA (phorbol 12myristate 13-acetate, ab120297) was purchased from Abcam (Abcam, Cambridge, UK). Blocking antibody for TLR-3 (ab17264), TLR-2 (ab16894), and TLR-4 (ab30667) were purchased from Abcam (Abcam, Cambridge, UK). Primary antibodies for GAPDH (60004-1-lg), $\beta$-actin (66009-1-Ig), and TLR-6 (22240-1-AP) were purchased from Proteintech Group, Inc. (Proteintech, Wuhan, China). Primary antibodies for TLR-1 (abs135699) were purchased from Absin Bioscience Inc. (Absin, Shanghai, China). Primary antibodies for P65(\#8242), p-P65 (\#3033), GST (\#3368, \#2624 and \#2625),

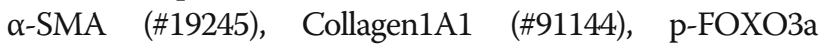
(\#9466), p-Smad3 (\#9520), p-Smad2(\#18338), mTOR (\#2983), p-JNK (\#4668), p-P38 (\#4511), P38 (\#8690), p-ERK (\#4370), ERK (\#4695), p-PI3K (\#4228), and PI3K (\#4257) were obtained from cell signaling (Cell-Signaling Technology, Boston, USA). Primary antibodies for TLR-2 (ab209217), F4/ 80 (ab6640), Fibronectin (ab268021), CD68 (ab213363), FOXO3a (ab109629), Smad3 (ab40854), Smad2 (ab33875), p-STAT5 (ab32364), STAT5 (ab32043), p-STAT3 (ab76315), STAT3(ab68153), p-mTOR (ab109268), JNK (ab179461), p-AKT1 (ab108266), and AKT1 (ab108202) were purchased from Abcam (Abcam, Cambridge, UK). Corresponding HRP-conjugated secondary antibodies were purchased from Santa Cruz (Santa Cruz Biotechnology, Dallas, TX, USA). Alexa Fluor 488 and 594-conjugated secondary antibodies for immunofluorescence were purchased from Abcam (Abcam, Cambridge, UK). Recombinant HBeAg domains (ArD, $\Delta$ RP-E, $\Delta 1-17-E, \Delta 29-96-E$, and $\Delta 122-143-E$ ) were obtained from Dia-An Biotech (Dia-An Biotech, Wuhan, China). Clophosome-A clodronate liposomes (Anionic, $7 \mathrm{mg} / \mathrm{ml}$, F70101C-A) and control liposomes (F70101-N) were purchased from FormuMax (Sunnyvale, CA, USA).

\section{RNA interference}

Small interfering (si) RNA targeting the human TLR-2 (seq-1: 5'-TTTGATGACTGTACCCTTAAT-3'; seq-2: 5'-GGAA GATAATGAACACCAA-3'; seq-3: 5'-GGCTTCTCTGTC TTGTGAC-3'), mouse TLR-1 (seq-1: 5'-CCGTCCCAAG TTAGCCCATTT-3'; seq-2: 5'-GCCTTCAGGATGTTCA ATTAT-3'; seq-3: 5'-CATCCTCTCATTGTCCAAGCT-3'), mouse TLR-6 (seq-1: 5' -CAATACCACCGTTCTCCATTT3'; seq-2: 5'-GGAATGGTTTGAAGAACTT-3'; seq-3: 5' CCGGTGGAGTACCTCAATATT-3'), mouse TLR-3 (seq1: 5'-GCTGAGCAGTTTGAATATA-3'; seq-2: 5'-CCAC CTACCAACTTTACAA-3'; seq-3: 5'-CACTCCACATCA TTATTAT-3'), human TLR-1 (seq-1:5'-GCTCATTTGAAT ATCAGCAA-3'; seq-2: 5'-ACTTAAGGGCAGCCATTA ATA-3'; seq-3: 5'-GATGAAGTCTCTGCAACAATT-3'), human TLR-6 (seq-1:5'-GGTCTTATTCATGTTCCAA-3'; seq-2: 5'-CAAAGAACCTATTGTTAAA-3'; seq-3: 5' GGTGCTTACAACTGACTAA-3') sequences, and negative control siRNA were purchased from Genepharma (Pudong new area, Shanghai, China). RNAis were added to cells accompany with the lipofectamine MAX (Invitrogen, Camarillo, CA, USA) based on the manufacturer's protocol. After interfering for $48 \mathrm{~h}$, protein knockdown efficiency was analyzed by western blot.

Quantitative real-time PCR (qRT-PCR), library preparation, and sequencing of RNA

Total RNA extraction, qRT-PCR, and RNAseq were performed as we previously described [10]. Sequences of the primers for qRT-PCR are listed in Table 2. The expression profile of growth factors, cytokines, chemokines, and TLRs were selected, and the corresponding heat map was drawn.

\section{Co-immunoprecipitation (Co-IP) and western blot analysis} According to the manufacturer's protocols, Co-IP was performed using a Capturem IP \& Co-IP Kit (Takara, Kusatsu, Japan). Briefly, per $10^{6}$ cells were lysed by $200 \mu \mathrm{l}$ lysis/equilibration buffer mixed with protease inhibitor cocktail on ice for $30 \mathrm{~min}$. Cell lysis supernatant was obtained after centrifuging at 17,000g for $10 \mathrm{~min}$. Then, the supernatant or mixed recombinant proteins were incubated with GST or TLR-2 antibody or isotype IgG (Cell Signalling Technology, Boston, 
Table 2 Primers used for quantitative real-time PCR

\begin{tabular}{|c|c|c|}
\hline Gene & Forward primer & Reverse primer \\
\hline Homo-IL-6 & CCTGAACCTTCCAAAGATGGC & TTCACCAGGCAAGTCTCCTCA \\
\hline Homo-TNF-a & GAGGCCAAGCCCTGGTATG & CGGGCCGATTGATCTCAGC \\
\hline Homo-COL1A1 & TAAAGGGTCACCGTGGCTTC & GGGAGACCGTTGAGTCCATC \\
\hline Homo-a-SMA & ATGCCTCTGGACGCACAACT & CCCGGACAATCTCACGCTCA \\
\hline Homo-Fibronectin & GGGTCTCCTCCCAGAGAAGT & GTTGGGGAAGCTCGTCTGTC \\
\hline Homo-GAPDH & GCACCGTCAAGGCTGAGAAC & TGGTGAAGACGCCAGTGGA \\
\hline Mus-IL-6 & GCCTTCTTGGGACTGATGCT & GCCATTGCACAACTCTITTCTCA \\
\hline Mus-TNF-a & CGGGCAGGTCTACTTTGGAG & ACCCTGAGCCATAATCCCCT \\
\hline Mus-IFN- $\gamma$ & GGGTTGTATCTGGGGGTGGG & GTCACTGCAGCTCTGAATGTTCTT \\
\hline Mus-IL-10 & GCTCTTGCACTACCAAAGCC & CTGCTGATCCTCATGCCAGT \\
\hline Mus-TGF- $\beta 1$ & AGGGCTACCATGCCAACTTC & CCACGTAGTAGACGATGGGC \\
\hline Mus-Ccl-2 & САCTCACCTGCTGCTACTCA & GCTTGGTGACAAAAACTACAGC \\
\hline Mus-Fibronectin & ACCTTGATCTCCCAAGCACG & CGTCAGGTGCTGTAGTCTGT \\
\hline Mus-Col1A1 & сCCTGGTCCCTCTGGAAATG & GGACCTTTGCCCCCTTCTTा \\
\hline Mus-a-SMA & TTCGTGACTACTGCCGAGC & GTCAGGCAGTTCGTAGCTCT \\
\hline Mus-GAPDH & TGTCTCCTGCGACTTCAACA & GGTGGTCCAGGGTTTCTTACT \\
\hline Homo-TLR-1 & GGAGGCAATGCTGCTGTTCA & GCCCAATATGCCTITGTTATCCTG \\
\hline Homo-TLR-2 & CTCCCAGCAGGAACATCTGCTA & CCAGGAATGAAGTCCCGCTTA \\
\hline Homo-TLR-3 & CCTGATGAAATGTCTGGATTTGGA & AACAGTGCACTTGGTGGTGGAG \\
\hline Homo-TLR-4 & CTGGGTGTGTTTCCATGTCTCA & TGCGGACACACACACTITCAAATA \\
\hline Homo-TLR-5 & GATGCTACTGACAACGTGGCTTC & AAGCTGGGCAACTATAAGGTCAGG \\
\hline Homo-TLR-6 & CTGTCTGCATTAGCCCTTCCTTG & TGTGGAAGAATGTGCCGTTTG \\
\hline Homo-TLR-7 & TTCAACCAGACCTCTACATTCCATT & GCAGTCCACGATCACATGGTT \\
\hline Homo-TLR-8 & CTITGCAGAGGCTAATGGATGAGAA & CTGCCGTAGCCTCAAATACTGAGAA \\
\hline Homo-TLR-9 & CCGTGACAATTACCTGGCCTTC & CAGGGCCTTCAGCTGGTTTC \\
\hline Mus-TLR-1 & TGACCTGCCCTGGTATGTGAG & GGCAGAATCATGCCCACTGTA \\
\hline Mus-TLR-2 & GAGCATCCGAATTGCATCACC & CCCAGAAGCATCACATGACAGAG \\
\hline Mus-TLR-3 & AAATCCTTGCGTTGCGAAGTG & TCAGTTGGGCGTTGTTCAAGA \\
\hline Mus-TLR-4 & CATGGATCAGAAACTCAGCAAAGTC & CATGCCATGCCTTGTCTTCA \\
\hline Mus-TLR-5 & GCTTGGAACATATGCCAGACACA & AAAGGCTATCCTGCCGTCTGAA \\
\hline Mus-TLR-6 & AATGGTACCGTCAGTGCTGGAAATA & TGGCTCATGTTGCAGAGGCTA \\
\hline Mus-TLR-7 & CTITGAACTGTGATGCTGTGTG & ACCTITGTGTGCTCCTGGACCTA \\
\hline Mus-TLR-8 & ACGGCTTGCCATCTTGGTC & AGTGGCAAATGTTCTTAGGGATTGA \\
\hline Mus-TLR-9 & GAGACCCTGGTGTGGAACATC & ACTGCAGCCTGTACCAGGAG \\
\hline
\end{tabular}

MA, USA) overnight at $4^{\circ} \mathrm{C}$. In the second day, samples (pre-incubated with antibody) were centrifuged using an equilibrated spin column and washed with $100 \mu \mathrm{l}$ Wash Buffer. Eluted proteins were analyzed by western blot using GST or TLR-2 primary antibody. Recombinant human TLR-2 (H-TLR-2, 2616-TR) and mouse TLR-2 (M-TLR-2, 1530-TR) were purchased from R\&D Systems (Minneapolis, MN, USA). Western blot assay was performed as we described previously [10].
Enzyme-linked immunosorbent assay (ELISA) and liver enzyme assays

Based on the manufacturer's instructions, mouse IL-6 (KMC0061, Invitrogen, Carlsbad, CA, USA), mouse TNF- $\alpha$ (KMC3011, Invitrogen, Carlsbad, CA, USA), mouse IFN- $\beta$ (439407, BioLegend, Inc. San Diego, CA), human IL-6 (Proteintech, Wuhan, China), and human TNF- $\alpha$ (Proteintech, Wuhan, China) in cell-culture supernatants were measured by commercially available ELISA kits. Serum alanine aminotransferase (ALT) and 
aspartate aminotransferase (AST) concentrations were determined using commercially available kits purchased from Nan Jing Jan Cheng Biochemical Institute (Nanjing, China).

\section{Histopathologic evaluation and immunohistochemistry} Liver specimens from biopsies or surgeries were fixed with formalin then embedded in 5 - $\mu$ m-thick paraffin sections. Blinded to the clinical data, a histopathologic assessment was evaluated by a senior hepatologist for all CHB patients. The METAVIR score system was applied for differentiating hepatic fibrosis and inflammatory activity via Masson's trichrome and hematoxylin-eosin staining [20, 21]. Besides, immunohistochemical staining was detected as previously described [22]. The positive area rates were assessed by Image-Pro Plus 5.0.

\section{Immunofluorescence}

NF- $\mathrm{kB}$ nuclear translocation and $\mathrm{HBeAg}$ cellular localization were detected with monoclonal antibody to P65, and GST tag. For NF-kB nuclear translocation, Alexa Fluor 488 or 594-conjugated secondary antibodies (Abcam, Cambridge, UK) were incubated for $2 \mathrm{~h}$. Nuclei were stained with 4',6diamidino-2-phenylindole (DAPI, Abcam, Cambridge, UK). Double immunofluorescence staining of $\alpha$-SMA and F4/80 was conducted on liver cryosections and incubated overnight with primary rat anti-mouse F4/80 (Abcam, Cambridge, UK) and rabbit anti-mouse- $\alpha$-SMA (Cell-Signaling Technology, Boston, USA) and then with secondary antibodies and DAPI. Immunolocalization of Desmin and ki67 was performed on liver cryosections and incubated with primary rat anti-mouse ki67 (Thermo Fisher Scientific, Waltham, MA) and rabbit anti-mouse-Desmin (Cell-Signaling Technology, Boston, USA). Images were captured using a fluorescence microscope (Olympus BX63, Tokyo, Japan) or confocal fluorescence microscopy (Leica TCS SP8).

\section{Preparation of the conditioned medium}

The medium collected from control and activated macrophages was defined as the conditioned medium (CM). After U937 cells were cultured in the presence of PMA (Abcam, Cambridge, UK) at a final concentration of 50 $\mathrm{ng} / \mathrm{ml}$ for $24 \mathrm{~h}$, most of the suspended cells differentiated into macrophages and attached to the plate bottom. Next, the adherent cells were washed twice with PBS and cultured with a serum-free medium. Macrophages were maintained in a serum-free medium throughout the experimental period as control or incubated with $\mathrm{HBeAg}$ for $24 \mathrm{~h}$ to activate macrophages. CM collected from control (CM-C) and activated macrophages (CME) was filtered with a $0.45-\mathrm{mm}$ membrane filter before being added to LX-2 cells.

\section{Hepatic stellate cell migration assay}

HSC migration was measured by transwell assays. About $10^{4}$ HSCs were suspended in a medium supplemented with 1\% FBS on the upper chambers of the 24-well transwell plate (pore diameter $8 \mu \mathrm{m}$ ). Lower chambers were supplemented with $10 \%$ FBS and (a) serum-free medium which has been incubated at $37{ }^{\circ} \mathrm{C}$ in an incubator with $5 \% \mathrm{CO}_{2}$ for $24 \mathrm{~h}$ to keep the same conditions as $\mathrm{CM}$, (b) serum-free medium with $\mathrm{HBeAg}(2 \mu \mathrm{g} / \mathrm{ml})$, (c) CM-C, and (d) CM-E. Transwell plates were maintained in an incubator for $24 \mathrm{~h}$ and cell migration was estimated by mean values of five randomly chosen fields captured on the lower surface of the filters.

\section{Cell proliferation assay}

The relative proliferation rates of the hepatic stellate cell were determined by Cell Counting Kit-8 (CCK-8) assay (Vazyme, Nanjing, China). HSCs were seeded in 96-well plates at 2000 cells/well and incubated overnight. After the standard cell culture medium was replaced by the medium mentioned in the HSC migration assay, HSCs were incubated for another $24 \mathrm{~h}$. After removing the culture medium, CCK- 8 solution, diluted with FBS-free high-glucose DMEM at a ratio of 1:9, was added to each culture well and incubated for $1 \mathrm{~h}$. Optical density (OD) was determined at $450 \mathrm{~nm}$ using a microplate reader (Bio-Rad Model 550, CA, USA). Relative cell proliferation rate was calculated as follows: [(OD CM treated group - OD blank group)/(OD control group - OD blank group)] $\times 100 \%$. Each group was performed in sextuplicate and repeated three times.

\section{Gel contraction assay}

Contractility of HSCs was evaluated using collagen gel lattices in a plastic 24-well culture plate. Collagen gels were made by mixing type I rat-tail collagen (BD Bioscience, Bedford, MA), $10 \times$ DMEM (Solarbio Science \& Technology, Beijing, China) and $0.1 \mathrm{~mol} / \mathrm{L} \mathrm{NaOH}$. The collagen solution was mixed with a HSC suspension to a final solution as collagen concentration of $1 \mathrm{mg} / \mathrm{ml}$ and cell density of $2 \times 10^{5}$ cells $/ \mathrm{ml}$. Five hundred microliters of mixed collagen gel solution was added into each well of a 24-well culture plate and was incubated for $1 \mathrm{~h}$ at $37^{\circ} \mathrm{C}$ to allow gelation. Collagen gel was exposed to a complete culture medium $(0.5 \mathrm{ml} /$ well $)$ and incubated in an incubator overnight. Then, cells in collagen gel were cultured with a serum-free medium for $4 \mathrm{~h}$. After washing 3 times with PBS, the collagen gel was detached from the periphery of the wall of each well using a 10- $\mu$ l micropipette tip. The cell culture medium was replaced by serum as mentioned above, and then cells in collagen gel were incubated for another $24 \mathrm{~h}$. Each gel was photographed and analyzed with Image-Pro Plus 5.0. 
Contractility of HSCs was measured as follows: $100 \%$-gel surface area/well basal area $\times 100 \%$.

\section{Phospho-protein profiling by phospho-antibody array} Lysates from LX-2 cells treated with CM-C, CM-C plus HBeAg $(2 \mu \mathrm{g} / \mathrm{ml})$, and CM-E were tested by the Phospho Explorer Antibody Array (PEX100, Full Moon Biosystems Inc.) according to the manufacturer's protocol. The phosphorylation ratio of each marker in different groups was analyzed as previously described [23].

\section{Cytokine determination by magnetic multiplex assay}

Inflammation cytokines in the cell-culture supernatants were assessed by a Magnetic Luminex Performance Assay (R\&D Systems) following the manufacturer's guidelines. A Luminex X-200 (Luminex, Austin, TX) was used to read the multiplex assay. Absolute cytokine concentrations were determined using 5-parameter logistic curve fits in the R\&D Analyte Software.

\section{Prediction of surface accessible peptide}

Emini surface accessibility prediction tool of the Immune Epitope Database (IEDB) was applied to predict the surface accessible peptide of the core domain of HBeAg ( $\triangle$ RP-E) using default threshold level 1.0 [24].

\section{Statistical analysis}

Statistical analysis was performed with SPSS v22.0 software (SPSS Inc, Chicago, USA). Continuous variable results were expressed as mean \pm standard deviation and categorical variables as the frequency or percentage. Student's $t$ test or one-way analysis of variance (ANOVA) was used to analyze significant differences between groups according to at least three independent experiments. Intergroup differences for clinical data were assessed using the chi-squared test, Mann-Whitney test, and Student's $t$-test appropriately. Relationships between the parameters were characterized using the Spearman correlation coefficients. $P<0.05$ was considered to be statistically significant.

\section{Results}

TLR-2 is the direct binding receptor of HBeAg for macrophage activation

Our previous research has found $\mathrm{HBeAg}$ can induce macrophage activation [10]. To further analyze the recognition receptor of HBeAg in macrophages, we firstly detected the kinetics of typical cytokines at the dose of $2 \mu \mathrm{g} / \mathrm{ml}$ so as to determine the best detection time point (Fig. 1A-F). The expression of TNF- $\alpha$ and IL-6 in macrophages was induced at the earliest time point $(2 \mathrm{~h})$, and then maximal levels were reached approximately at $4 \mathrm{~h}$ after the stimulation of $\mathrm{HBeAg}$. Therefore, the following data were detected at $4 \mathrm{~h}$ after $\mathrm{HBeAg}$ treatment.
To understand the regulatory role of HBeAg on macrophage comprehensively, RNAseq analysis was applied. Notably, except for inflammation cytokines, a significant change of TLRs was also observed as demonstrated in the heat map (Fig. 1G). Therefore, the absolute expression of TLRs was analyzed in mouse and human macrophages by qRT-PCR to further verify this finding (Table 3). We found that TLR expression can be roughly divided into 3 levels: comparable high (TLR-2), medium (TLR-1, TLR-4, TLR-6, TLR-7, and TLR-9), or very low (TLR-3, TLR-5, and TLR-8). TLR-2 expression was upregulated most obviously in THP-1 cells pretreated with PMA (4.05 folds), whereas TLR-3 expression was increased most pronouncedly in RAW 264.7 macrophages (55.53 folds). As co-receptors of TLR-2, the expression of TLR-1 and TLR- 6 was enhanced slightly (1-3 folds) in all of three cell lines. By contrast, $\mathrm{HBeAg}$ induced drastically reduction in expression levels of TLR- 5 and TLR-7 (29-64\%). Since the expression of TLR-5 in all three macrophage cell lines was extremely low and decreased significantly after $\mathrm{HBeAg}$ treatment, it indicates that its role in $\mathrm{HBeAg}$ recognition is negligible.

To define whether HBeAg can interact with TLRs, although it was able to regulate their expression, we firstly identified the location of HBeAg when it activated macrophages by immunofluorescence assay. As shown in Fig. $1 \mathrm{H}, \mathrm{HBeAg}$ predominantly located at the cell boundaries, demonstrating that TLRs may play some roles in this process. Next, macrophages were pretreated with inhibitors of TLR-2 (C29), TLR-4 (resatorvid), TLR-7/9 (hydroxychloroquine sulfate), and TLR-8 (CUCPT9b) for $30 \mathrm{~min}$ and subsequently treated with HBeAg. We observed the cell morphology and expression of different cytokines in order to screen the potential binding receptors. As displayed in Fig. 1I, macrophages pretreated with hydroxychloroquine sulfate and CU-CPT9b continued to become stretched and multilateral, indicating the activation of macrophages [25], while macrophages pretreated with C29 and resatorvid were not activated and kept their round morphology. Meanwhile, in accordance with the morphology, the levels of inflammatory cytokines in C29 and resatorvid pretreatment groups exhibited a significant reduction as compared with the group treated with $\mathrm{HBeAg}$ alone (Fig. 1J-P). Our previous studies verified that $\mathrm{HBeAg}$ promoted cytokine production via NF-kB signal pathway [10]. Therefore, we further tested the phosphorylation levels and nuclear translocation of p65 in macrophages treated with above-mentioned multiple inhibitors. As demonstrated in Fig. 1Q-R, macrophages pretreated with hydroxychloroquine sulfate and CU-CPT9b showed no or only slight attenuation in phosphorylation levels of p65. However, the phosphorylation and nuclear translocation of p65 were greatly declined in C29- or 


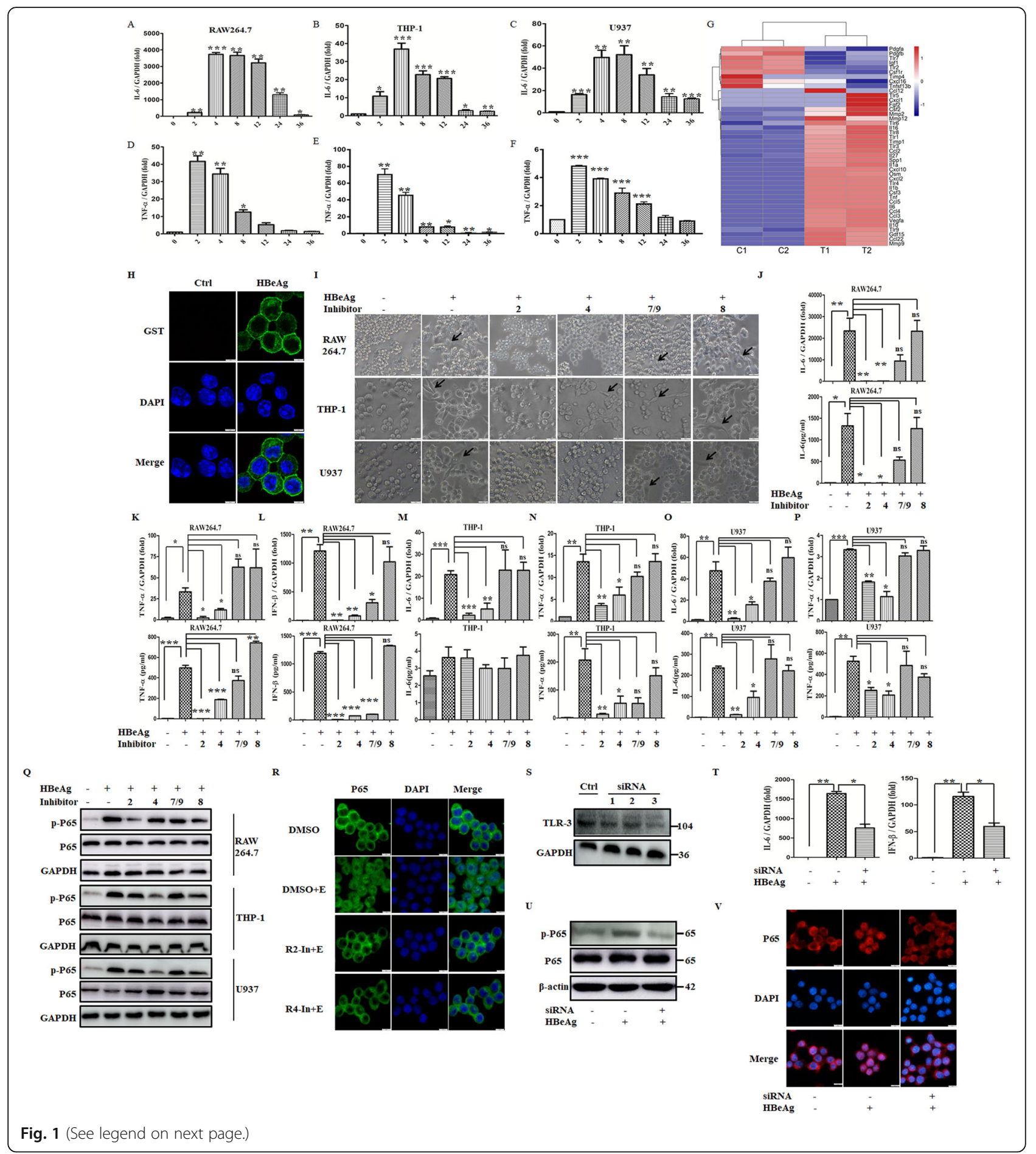


(See figure on previous page.)

Fig. $1 \mathrm{HBeAg}$ regulated the expression of multiple TLRs in macrophages, while the inflammatory response of HBeAg-induced macrophages was inhibited by TLRs. RAW 264.7 macrophages were stimulated with HBeAg $(2 \mu \mathrm{g} / \mathrm{ml})$ at different time points, and then the expression of IL-6 and TNF-a was detected respectively using qRT-PCR (A, D). THP-1 (B, E) and U937 cells (C, F) were pretreated with PMA at a final concentration of 50 $\mathrm{ng} / \mathrm{ml}$. After replacing the fresh medium, they were stimulated with HBeAg $(2 \mu \mathrm{g} / \mathrm{ml})$ at different time points, and the expression of IL-6 and TNFa was detected respectively using qRT-PCR. RAW264.7 macrophages were stimulated with HBeAg for $24 \mathrm{~h}$, and RNA sequencing assay was performed. The expression profile of growth factors, cytokines, chemokines, and TLRs were selected and displayed (G). $\mathbf{H}$ After incubation with HBeAg for $1 \mathrm{~h}$ at $4^{\circ} \mathrm{C}$, RAW 264.7 macrophages were fixed with $1 \%$ paraformaldehyde for $20 \mathrm{~min}$ at room temperature. After blocking, cells were incubated with Alexa Flour 488 -conjugated primary antibody for $1 \mathrm{~h}$ at $37^{\circ} \mathrm{C}$ followed by DAPI for nuclear staining, then captured using a confocal fluorescence microscopy. RAW 264.7 macrophages and PMA-pretreated THP-1/U937 cells were treated with DMSO or inhibitors of TLR-2, 4, 8, 7/9 (10 $\mathrm{\mu M})$ for $30 \mathrm{~min}$. The cell morphology was analyzed after HBeAg treatment for $24 \mathrm{~h}$ (I). The arrows indicate activated macrophages. RAW 264.7 macrophages were firstly treated with DMSO or inhibitors of TLR-2, 4, 8, 7/9 for 30 min, and then they were treated with HBeAg for 4 $\mathrm{h}$. The expression and secretion of IL-6, TNF-a, and IFN- $\beta$ were tested by qRT-PCR and ELISA respectively (J-L). PMA-pretreated THP-1 (M-N) and U937 cells (-O-P) were treated with DMSO or inhibitors of TLR-2, 4, 8, 7/9 for $30 \mathrm{~min}$, and then they were treated with HBeAg for $4 \mathrm{~h}$. The expression and secretion of IL-6 and TNF-a were tested by qRT-PCR and ELISA respectively. Macrophages, including RAW264.7, PMA-pretreated

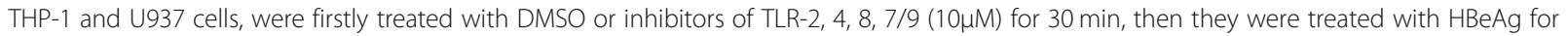
another $20 \mathrm{~min}$. The phosphorylation level of p65 was tested by western blot assay (Q). Additionally, the effect of TLR-2/4 inhibitors on the nuclear translocation of p65 was determined (R). The siRNAs for TLR-3 or negative control were transfected into RAW264.7 macrophages for $48 \mathrm{~h}$, and then the cells were treated with HBeAg for $4 \mathrm{~h}$. The expression of TLR-3 was tested by western blot assay (S), and the level of IL-6 and IFN- $\beta$ (T) was tested by qRT-PCR. The siRNAs for TLR-3 or negative control were transfected into RAW264.7 macrophages for $48 \mathrm{~h}$, and then the cells were treated with HBeAg for $20 \mathrm{~min}$. The phosphorylation level and nuclear translocation of p65 were tested separately $(\mathbf{U}-\mathbf{V})$. ${ }^{*} P<0.05$, ${ }^{* *} P<$ $0.01,{ }^{* * *} P<0.001$

resatorvid-pretreated cells. Moreover, to evaluate the involvement of TLR-3 (no corresponding inhibitor), RAW264.7 macrophages were transfected with TLR-3specific siRNAs. We confirmed a most evident reduction (>50\%) of TLR-3 using seq-3 on day 2 after transfection (Fig. 1S), so seq-3 was used in the following analysis. And the expression of IL- 6 and IFN- $\beta$ was blocked dramatically $(\sim 50 \%)$ following the transfection of TLR-3specific siRNAs (Fig. 1T). Consistently, the phosphorylation and nuclear translocation of p65 were also blocked as shown in Fig. $1 \mathrm{U}-\mathrm{V}$. Altogether, the above results signified that TLR-2/3/4 played crucial roles in the macrophage activation induced by HBeAg.

Next, we used antibody blocking experiments for further verification. As displayed in Fig. 2A, the production of IL-6 was weakened most significantly by TLR-2blocking antibody rather than TLR-3/4-blocking antibodies. Thus, we aimed at TLR-2 in the following analysis. Furthermore, we investigated the effect on hMDM using the siRNA knockdown of TLR-2. By day 2 , there was a most significant decrease in TLR-2 protein expression using seq-2 (Fig. 2B). In accordance with the above results, the knockdown of TLR-2 prevented TNF- $\alpha$ and IL- 6 production in the HBeAg stimulation group (Fig. 2C, D). Similar results could also be detected in mouse Kupffer cells pretreated with C29 (Fig. 2E, F). To determine whether $\mathrm{HBeAg}$ could interact with TLR2 directly, we firstly performed co-immunoprecipitation assays with recombinant proteins of the extracellular segment of TLR-2. Our data showed that HBeAg could directly interact with TLR-2 in vitro (Fig. 2G, H). Furthermore, HBeAg was also able to interact with endogenous TLR-2 in vivo (Fig. 2I).

Finally, to distinguish which co-receptor is involved in TLR-2-mediated recognition and activation by HBeAg, we specifically knocked down TLR-1 and TLR-6 (Fig. 2J

Table 3 The expression of TLR1-9 in RAW264.7, U937, and THP-1 cells

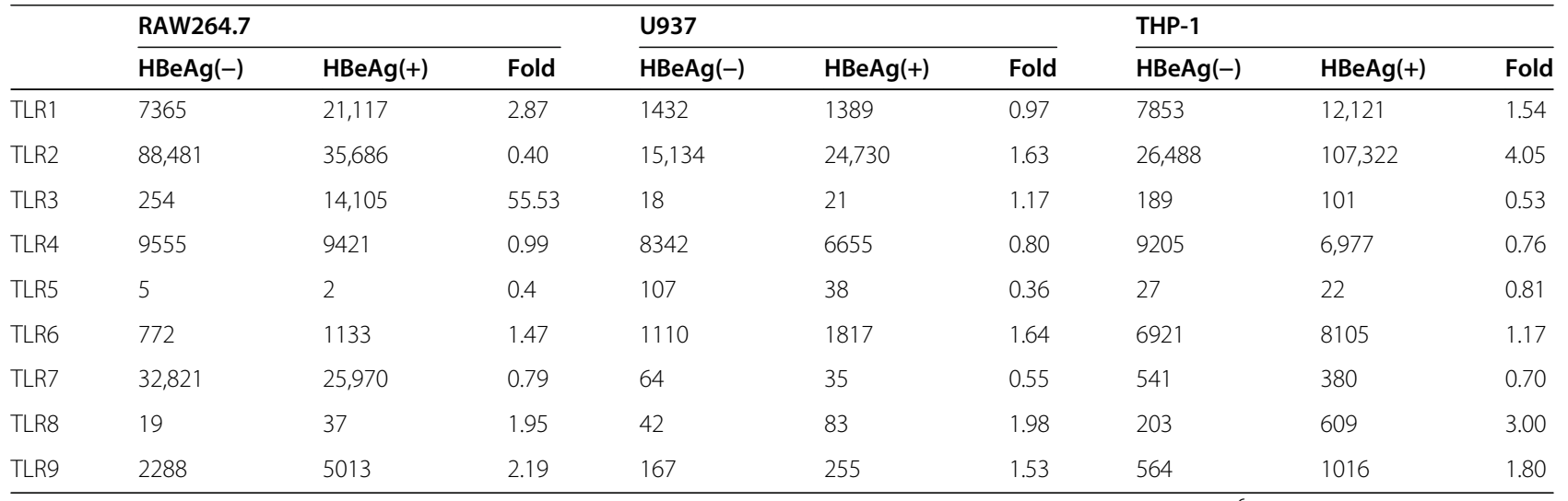

Note: The expression of TLRs was measured via Q-PCR. Copy numbers of TLR1-9 transcripts were normalized against GAPDH ( $\times 10^{6}$ copies GAPDH) 


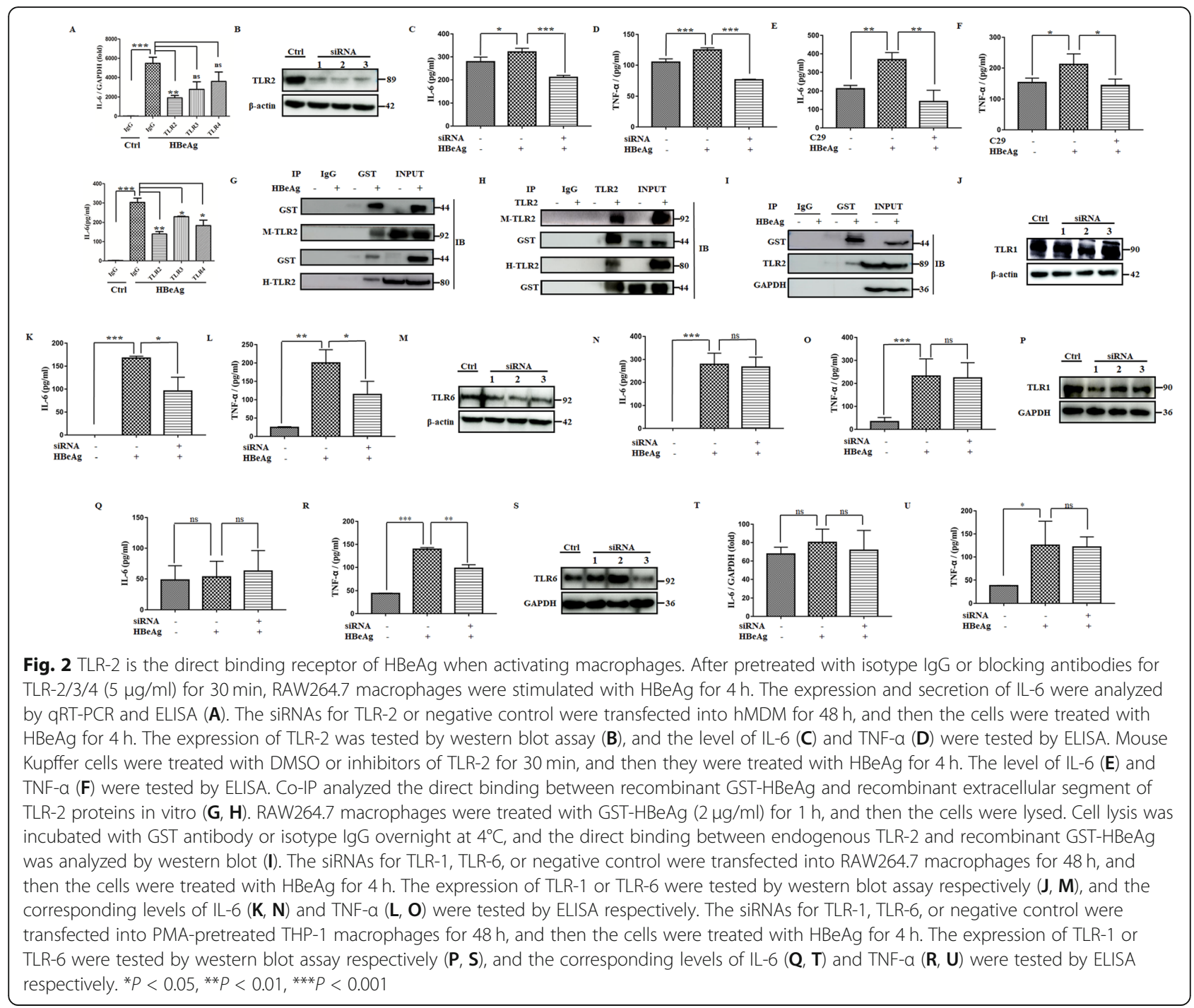

and M) and measured cytokines change. In RAW264.7 macrophages, the knockdown of targeted siRNAs for TLR-1 resulted in more significant inhibition of $\mathrm{HBeAg-}$ induced IL- 6 and TNF- $\alpha$ production as compared with that of TLR-6 (Fig. 2K, L, N, O). Similar results for TNF- $\alpha$ induction were observed in PMA-pretreated THP-1 cell line (Fig. 2P-U). These results suggest TLR1 may play a more important role in the activation of the HBeAg-induced TLR-2 signaling pathway.

\section{The C-terminal peptides of HBeAg played a key role in macrophage activation}

$\mathrm{HBeAg}$ (p17) is processed from precore precursor protein (p25) with $\mathrm{N}$ - and $\mathrm{C}$-terminal being truncated and shares a common core domain of 149 residues with HBcAg (p21) (Fig. 3A). However, the HBcAg is different from $\mathrm{HBeAg}$ based on our previous results, since it cannot significantly induce mouse macrophage activation
[10]. To eliminate the effect that may be caused by species differences, we added recombinant $\mathrm{HBcAg}$ to PMApretreated THP-1 and U937 cells for $4 \mathrm{~h}$. Consistently, we found the secretion and expression of IL- 6 and TNF$\alpha$ also exhibited no significant induction in both of these cell lines (Fig. 3B, C).

Next, we aimed to investigate the function domain of $\mathrm{HBeAg}$ for macrophage activation in order to further explain the immunogen difference between HBeAg and HBcAg. Accumulating data had shown that N-terminal propeptide of HBeAg determines the radically different molecular structure relative to $\mathrm{HBcAg}$, and arginine-rich domain (ArD) of HBcAg is a prerequisite for the IL-18 production [26]. Thus, we synthesized recombinant protein $\operatorname{ArD}$ and $\Delta$ RP-E $(\mathrm{N}$ terminal 10-residue propeptide deleted $\mathrm{HBeAg}$ ) and then treated macrophage with them. As shown in Fig. $3 \mathrm{D}$, the expression and secretion of IL- 6 and TNF- $\alpha$ 


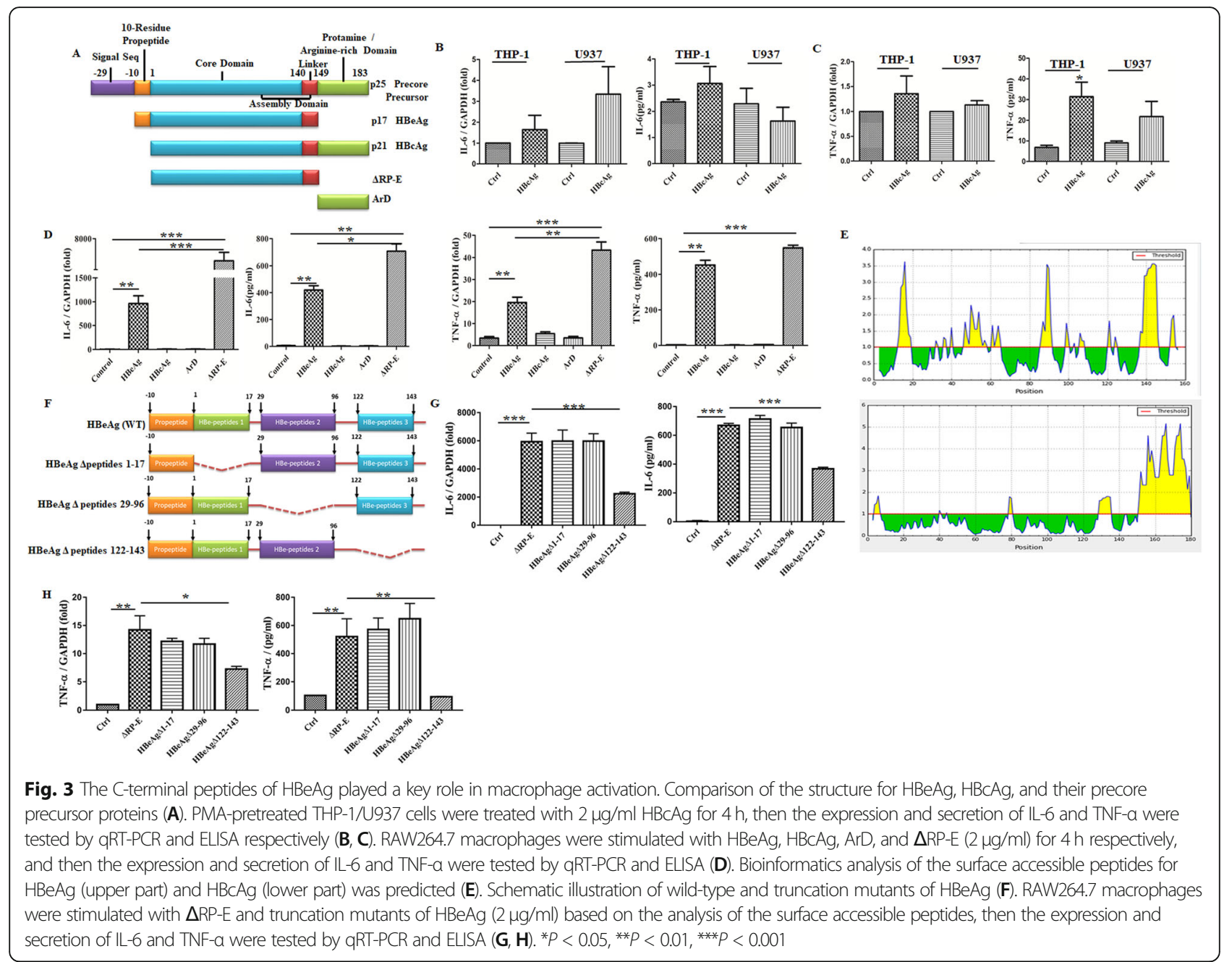

were more increased in the group of $\triangle \mathrm{RP}-\mathrm{E}$ stimulation than that of full-length $\mathrm{HBeAg}$, whereas $\mathrm{ArD}$ and $\mathrm{HBcAg}$ hardly triggered any changes compared with control. Moreover, we performed bioinformatics analysis for the surface accessible peptides, showing that the accessible peptides for $\mathrm{HBeAg}$ were scattered in three sections of the core domain (aa. 1-17, 29-96, 122-143), whereas for $\mathrm{HBcAg}$ it was concentrated in arginine-rich terminal (Fig. 3E). Thus, we speculated that the core domain of $\mathrm{HBeAg}$ was responsible for promoting the activation of macrophages, yet $\mathrm{HBcAg}$ adversely hided its immunogenicity due to extra ArD in this process. Furthermore, three recombinant $\mathrm{HBeAg}$ proteins which delete the above-mentioned accessible peptides were used to confirm their abilities in activating macrophages separately (Fig. 3F). $\Delta$ aa.(122-143)-E was minimally stimulatory for macrophages compared with the others, suggesting that aa. 122-143 in HBeAg was crucial for macrophage activation (Fig. 3G, H).
$\mathrm{HBeAg}$ promoted the activation of hepatic stellate cells in a macrophage-dependent manner

To analyze whether HBeAg can activate HSCs directly or in a macrophage-dependent manner, we added CM from $\mathrm{HBeAg}$ activated macrophages to human LX-2 stellate cells for $24 \mathrm{~h}$ compared with $\mathrm{HBeAg}$ alone. To our surprise, no significant difference of levels of $\alpha$ SMA, collagen, and fibronectin was detected in different groups (Fig. 4A-C). The same results could also be detected from primary hepatic stellate cells treated with CM from RAW264.7 cells (Fig. 4D). In the ongoing process of hepatic fibrosis, activated HSCs exert profibrosis effects not only by means of fibrillar extracellular matrix accumulation, but also by their proliferation, motility, and contractile phenotypes [27]. As shown in Fig. $4 \mathrm{E}$, cells treated with $\mathrm{CM}-\mathrm{E}$ exhibited the greatest chemotaxis toward serum, while cells treated with $\mathrm{HBeAg}$ did not display obvious chemotaxis compared with control. Additionally, the proliferation of HSCs also showed the same trend as the motility (Fig. 4G). 


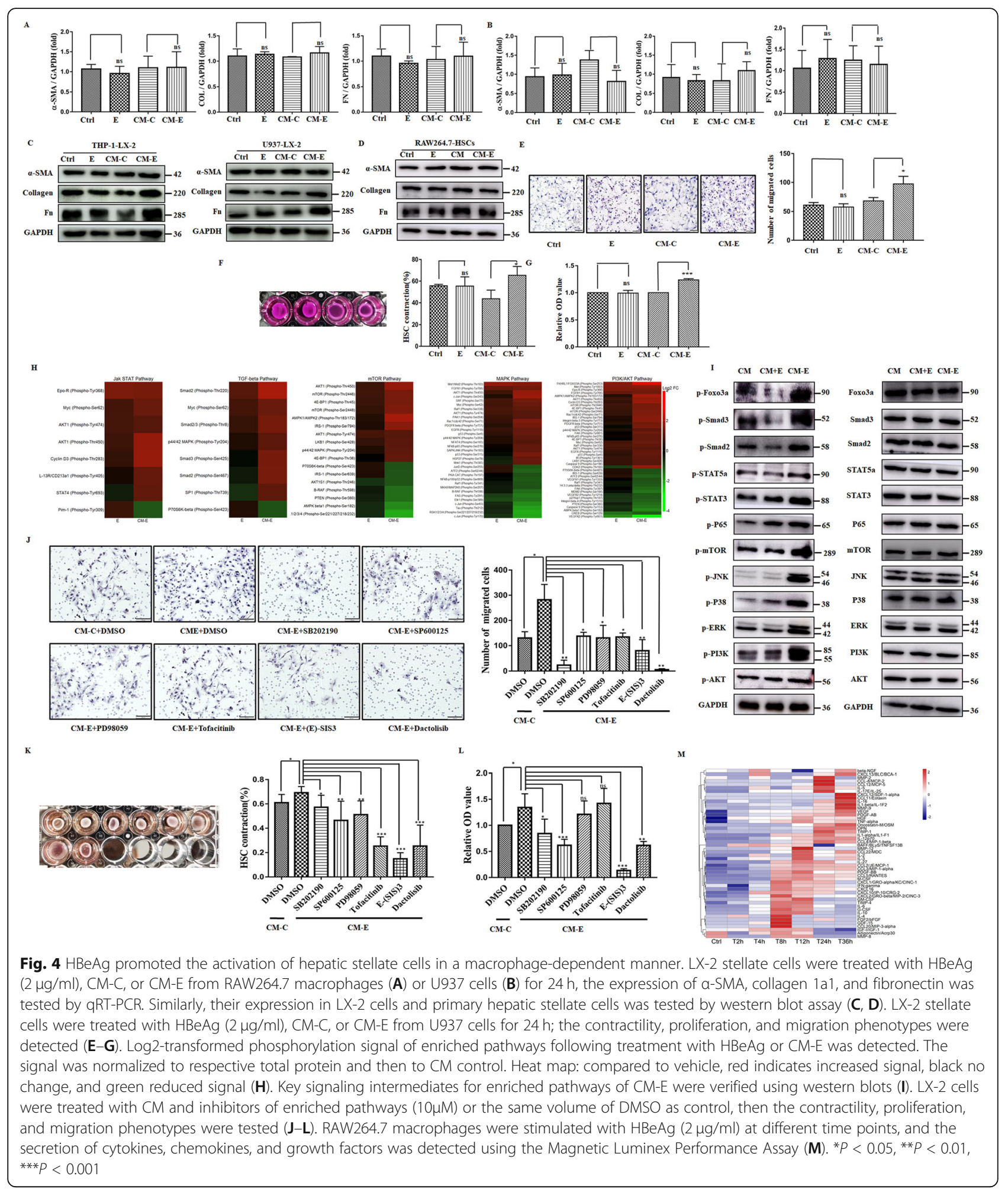


Moreover, the surface area of the collagen lattice in control showed an evidently reduced, and the extent is similar with HSCs treated with $\mathrm{HBeAg}$ (Fig. 4F). In contrast, collagen lattice treated with CM-E caused more evident contraction as compared with lattice treated with CM-C.

\section{Conditioned medium from HBeAg-treated macrophages mediated HSC activation through different signal pathways}

To investigate mechanisms that are regulated by CM-E for the activation of HSCs, we used a Phospho Explorer antibody microarray to detect and analyze phosphorylation events under specific conditions. Overall, we identified 92 proteins with at least $50 \%$ reduced, and 90 proteins with at least $100 \%$ increased phosphorylation. KEGG and pathway mapping analysis was further used to analyze these pivotal pathways. As compared with $\mathrm{CM}$ or $\mathrm{CM}$ with $2 \mu \mathrm{g} / \mathrm{ml} \mathrm{HBeAg}$, pathways that were significantly altered by CM-E were ErbB and mTOR signaling pathways, which mainly consist of MAPK, JAKSTAT, and PI3K-AKT signaling pathway. Besides, the TGF- $\beta$ signaling pathway was the main pathway that was only affected by CM-E. The specific phosphorylation sites of the aforementioned pathways are illustrated in Fig. $4 \mathrm{H}$, and key signaling intermediates were verified using western blots (Fig. 4I). To further reveal the signal pathway responsible for the HSC phenotype induced by CM-E, we pretreated LX-2 cells with the inhibitors of these pathways for $30 \mathrm{~min}$ and subsequently treated with CM-E. Though all of them may play some roles in the phenotype induced by CM-E, a more predominant effect was detected in PI3K-AKT-mTOR and p38 MAPK signaling pathway for motility (Fig. 4J) and the Smaddependent TGF- $\beta$ signaling pathway for proliferation and contraction of stellate cells (Fig. 4K, L). To analyze the soluble factors responsible for the phenotype, CM-E was screened for the level of various cytokines, chemokines, and growth factors using the Magnetic Luminex Performance Assay (Fig. 4M). Notably, soluble factors, such as CCL2, CCL5, CXCL10, and TNF- $\alpha$, exhibited apparent secretion as early as $4 \mathrm{~h}$ after stimulation and were 9-137 folds higher than those produced by control macrophages. In addition, they have previously been reported to be key regulators of inflammation and liver fibrosis $[15,28]$; hence, we have reason to believe that these soluble factors from macrophage supernatant induced by HBeAg may be key components of the activation of HSCs.

\section{$\mathrm{HBeAg}$ induced inflammation and fibrogenesis response in vivo via TLR-2 in macrophages}

To analyze the immunoreaction of $\mathrm{HBeAg}$ in vivo, C57BL/6 mice were intravenous injected with recombinant $\mathrm{HBeAg}$ $40 \mu \mathrm{g}$ for 4, 8, 12, and $24 \mathrm{~h}$. As shown in Fig. 5A, there is a few small inflammatory infiltrates, but no observable hepatic necrosis areas (a common phenomenon of LPS and ConAinduced hepatitis) were detected at 4-12 h, which was in line with the transient expression of cytokines (Fig. 5B-E), implying that $\mathrm{HBeAg}$ is involved in the induction of hepatic inflammation. Concomitantly, both serum ALT and AST were increased mildly at different detection time (Fig. 5F, G). Additionally, the effect of HBeAg on fibrogenesis was assessed in the acute $\mathrm{CCL}_{4}$ model in mice. Co-immunofluorescence of F4/80 and $\alpha$-SMA showed that $\mathrm{HBeAg}$ injection after $\mathrm{CCL}_{4}$ treatment aggravated macrophage infiltration and HSC activation. However, single $\mathrm{HBeAg}$ injection could not trigger HSC activation obviously (Fig. 5H). Meanwhile, HBeAg injection after $\mathrm{CCL}_{4}$ treatment contributed to the proliferation and motility of HSCs and elevated serum ALT (Fig. 5I, J). Therefore, $\mathrm{HBeAg}$ can promote the progression of liver injury and hepatic fibrosis rather than the leading cause of its initiation. To further elucidate the roles of macrophages in vivo, we depleted macrophages by injecting clodronatecontaining liposomes before $\mathrm{HBeAg}$ or $\mathrm{CCL}_{4}$ treatment. Nearly all macrophages were depleted at day 1 and day 4 by clodronate as evidenced by reduced protein expression of F4/80 (Fig. 5K). Macrophage depletion led to a significant reduction in the expression of growth factors, cytokines, chemokines, $\alpha$-SMA, and collagen in HBeAg treatment alone or the progression of fibrosis induced by $\mathrm{CCL}_{4}(\mathrm{Fig} .5 \mathrm{~L}-\mathrm{T})$. Finally, to verify the roles of TLR-2 in vivo, mice were pretreated with $\mathrm{C} 29$ before the administration of $\mathrm{HBeAg}$. We found the expression of IL- 6 , TNF- $\alpha$, and CCL-2 was significantly alleviated (Fig. $5 \mathrm{U}-\mathrm{W}$ ), but $\mathrm{IL}-10$ was upregulated in the liver (Fig. 5X).

\section{The level of $\mathrm{HBeAg}$ associated with inflammation and fibrosis degrees in patients infected with HBV}

To verify our results in patients infected with $\mathrm{HBV}$, we recruited 61 patients with $\mathrm{AHB}$ and 151 patients with $\mathrm{CHB}$. As an index of viral replication, the level of $\mathrm{HBeAg}$ was positively correlated with HBV DNA load in AHB patients (Fig. 6A). Moreover, the levels of serum ALT, AST were increased with the $\mathrm{HBeAg}$ in these patients (Fig. 6B, C).

Next, we analyzed the relationship between the level of $\mathrm{HBeAg}$ and fibrosis stages and inflammation grades in CHB patients. As shown in Fig. 6D, hepatic inflammation grades were higher in $\mathrm{HBeAg}^{+}$patients than $\mathrm{HBeAg}^{-}$patients; nevertheless, statistical significance could only be achieved between $\mathrm{G}=0$ and $\mathrm{G} \geq 1(P=$ 0.030). CD68, a marker for monocytes and macrophages, was estimated by immunohistochemical analysis in all of $\mathrm{HBeAg}^{+}$patients $(n=45)$ (Fig. $\left.6 \mathrm{E}\right)$. The positive area of CD68 was higher in patients with significant inflammation grades $(G \geq 2)$ (Fig. 6F), indicating its close relationship with hepatic inflammation activity in $\mathrm{CHB}$ patients. Meanwhile, a significant correlation was observed 


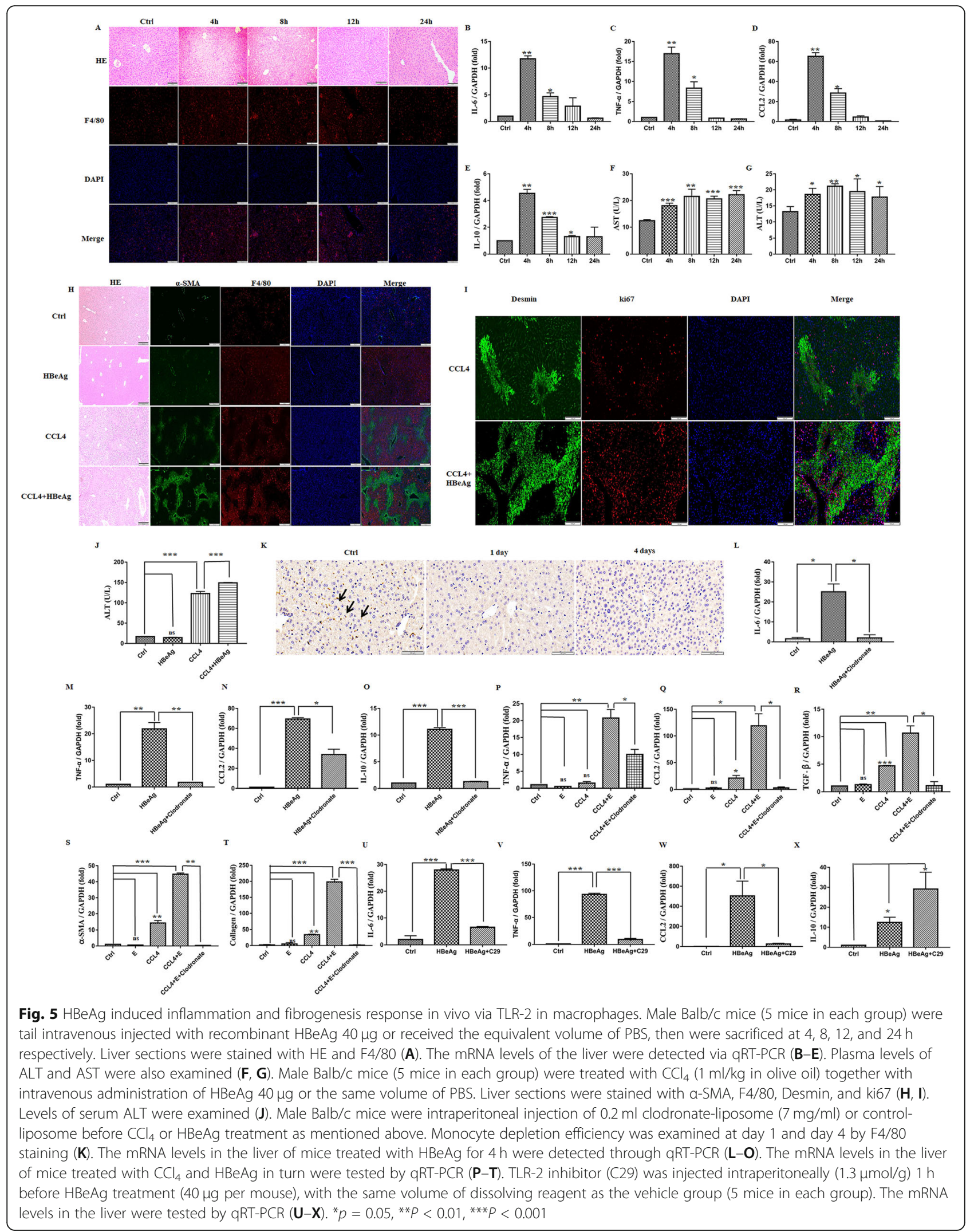




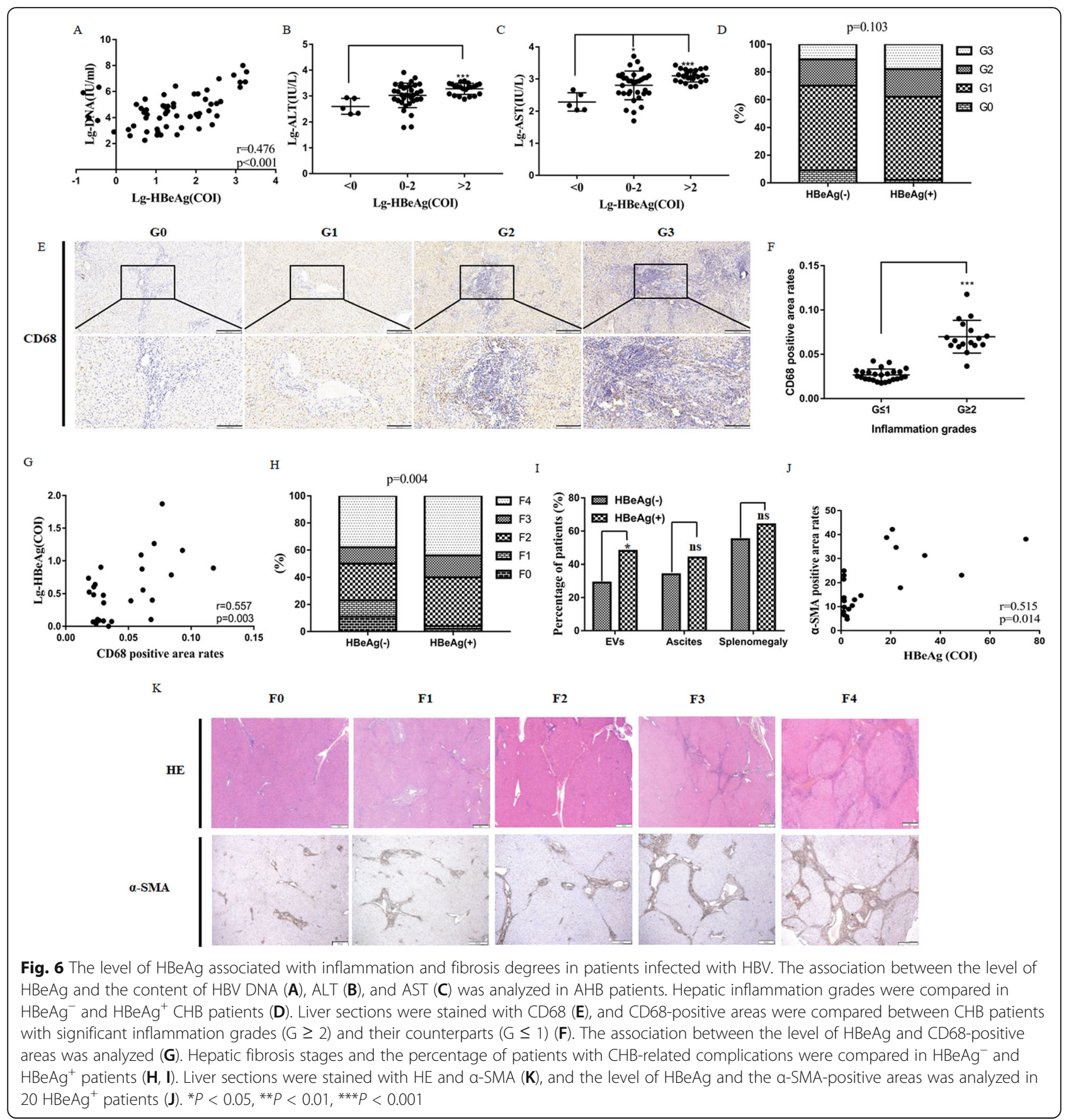

between the $\mathrm{CD}^{+} 8^{+}$cell infiltration and the level of HBeAg $(r=0.557, P=0.003$, Fig. 6G). Moreover, hepatic fibrosis was more severe in $\mathrm{HBeAg}^{+}$patients than $\mathrm{HBeAg}^{-}$patients $(P=0.004$, Fig. $6 \mathrm{H})$. Consistently, $\mathrm{HBeAg}^{+}$patients showed a higher incidence of the cirrhosis-related complications such as esophageal varices (EVs), ascites, and splenomegaly, even though only rates of EVs achieved statistical significance (Fig. 6I). Furthermore, $\alpha$-SMA was detected for $20 \mathrm{HBeAg}^{+}$patients (Fig. 6K). As demonstrated in Fig. 6J, its positive staining areas were correlated with the level of $\mathrm{HBeAg}$ positively $(r=0.515, P=0.014)$. Taken together, we demonstrated that $\mathrm{HBeAg}$ may act as a vital regulator of hepatic inflammatory and fibrosis response in patients infected with HBV.

\section{Discussion}

HBV infection is an important public health issue. The major harm of HBV infection lies in the persistent liver injury caused by the activation of the immune system, 
and concomitant wound-healing response, which will finally lead to the occurrence of hepatic cirrhosis and its related complications. Macrophages, as an important component of the innate immune system, represent the first line of defense against pathogens in the liver. During infection, macrophages can sense the presence of HBV pathogen-associated molecular patterns through PRRs, and further secrete a large spectrum of inflammatory cytokines to mediate inflammation response. Moreover, macrophages are also able to prompt an effective adaptive immunity and contribute to a vigorous $\mathrm{T}$ cell response as well as B cell-mediated antibody secretion. In addition, liver fibrosis is induced by sustained lowgrade injury during chronic HBV infections, and one of the most important mechanisms for its formation is the crosstalk between HSCs and macrophages in a paracrine manner [29]. Accumulating data have showed that macrophages play vital roles in both the injury and recovery phases of inflammatory scarring [30].

Sensing and responding to pathogens for macrophages are largely mediated by PRRs, including scavenger receptors, TLRs, RIG-like receptors, NOD-like receptors, and C-type lectins [31]. HBV particles and its related proteins could be detected and recognized by macrophages, thus activating surface and/or intracellular receptors to produce viral inhibitory cytokines [8]. Recently, only limited information exists in the direct interaction between $\mathrm{HBV}$ with macrophages in vivo and in vitro. It has been reported that TLR-2 and heparan sulfate proteoglycan were responsible for $\mathrm{HBcAg}$ recognition, thereupon resulting in the production of IL-6, IL-12p40, and TNF [5]. However, HBcAg only existed within infected hepatocytes or viral particles, and our data have confirmed that $\mathrm{HBcAg}$ cannot induce macrophage activation significantly in mouse or human macrophages. Thus, there might be other ways for macrophages to recognize HBV. Moreover, $\mathrm{HBsAg}$ can stimulate human blood monocytes in a CD14dependent manner [32], and the complex formation with albumin may increase its uptake by Kupffer cells [33]. Intriguingly, for dendritic cells, HBsAg internalization is mediated through the mannose receptor [34], so we may speculate the same viral protein is able to trigger immune response at diverse binding sites. The available evidence shows the interaction of $\mathrm{HBeAg}$ with mIL-1RAcP may trigger host IL-1 response by activating downstream NF- $\mathrm{B}$ s signal pathway by means of ІкB degradation [35]. In this study, we further verified that TLR-2 is the direct binding receptor of HBeAg when activating macrophages both in vivo and in vitro, and C-terminal peptides of HBeAg serve as molecular basis for the activation of macrophages induced by HBeAg. This finding provides a novel mechanism in HBVinduced macrophage activation.
On the other hand, HBV particles and its related proteins may repress immune response to a certain extent and contribute to persistent infection. Intriguingly, there are species-specific differences in this respect, which are mainly characterized by the difference of the expression of TLRs and their regulation induced by HBeAg in our study. In an un-activated state, the expression of several TLRs in mouse macrophage was higher than that in human macrophage, especially for TLR-2, TLR-7, and TLR-9. Therefore, our results indicated a more pronounced inflammation response in mouse macrophages compared with human macrophages, and this finding may explain that HBV can replicate persistently in human livers but not in mice under natural conditions. Moreover, some excellent reviews also specified that the differences in the structure, sequences, and localization patterns of TLRs may also determine divergent functions across different species [36-38]. Additionally, the mechanism of immune escaping induced by $\mathrm{HBeAg}$ might not be the same between mice and humans. We observed that TLR-2 displayed the highest expression in mouse macrophages, while its expression reduced most significantly after $\mathrm{HBeAg}$ stimulation. However, for human macrophages, HBeAg may mainly decrease the expression of TLR-3 which is associated with the IFN production. Overall, our results also verified the previous finding that HBV can downregulate TLR expression so as to inhibit the antiviral response from macrophages and facilitate immune tolerance [29]. Moreover, HBV replication could be abolished through the treatment of ligands for TLR-7 and TLR-5, implying these receptors may play pivotal roles in inhibiting HBV replication [39]. However, both of them were downregulated in both mouse and human macrophages treated with $\mathrm{HBeAg}$, suggesting another novel mechanism of immune escaping and tolerance induced by HBV. Aiming at the same goal, HBV may also facilitate anti-inflammatory responses in vivo directly. Kupffer cells in HBV-carrier mice expressed more IL-10 and mediated the systemic tolerance induction in an IL-10-dependent manner [40]. Consistently, at the peak of viremia, during the inhibition of lymphocyte activation, a peak of IL-10 was observed in the serum of patients infected with acute HBV [41]. In this study, HBeAg also induces the expression of IL-10 in the liver, while IL-10 was upregulated more pronouncedly in mice pretreated with TLR-2 inhibitors, indicating $\mathrm{HBeAg}$ may also target other signal pathway mediators in this process. Thus, the expression of TLR-2 may resist the formation of immune tolerance during the HBV infection. Consistently, primary human hepatocytes have recently been reported to sense HBV particles through TLR-2, leading to an activation of anti-HBV immune responses in vitro [42]. In the future, more attention should be paid in the mechanism and clinical 
significance in this field. Finally, Lang et al. find propeptide of HBeAg is identified as similar with the TIR motif, thereby suppressing TIR-mediated activation of the inflammatory responses by disrupting homotypic TIR:TIR interaction [43]. Accordingly, $\mathrm{HBeAg}$ is the most crucial protein in HBV-associated antigen activating macrophages, and the core domain ( $\triangle \mathrm{RP}-\mathrm{E})$ triggered more expression and secretion of cytokines when comparing with $\mathrm{HBeAg}$ and $\mathrm{HBcAg}$. In addition, C-terminal ArD is unique and the only surface accessible domain for $\mathrm{HBcAg}$, and the previous study indicates $\mathrm{HBcAg}$ may promote cytokine induction from macrophages in a ArD-dependent manner [5]. However, neither $\mathrm{HBcAg}$ nor $\mathrm{ArD}$ can induce macrophage activation significantly in this study, and we speculate ArD, just like propeptide of $\mathrm{HBeAg}$, may also play a crucial role in proinflammatory secretion inhibition. Altogether, it seems that activation and inhibition of immune response may co-exist in the process of HBV infection.

In HBV-infection microenvironments, activated macrophages are proved to be involved in liver fibrosis by activating HSCs directly or indirectly [31]. Actually, increased numbers of $\mathrm{CD}^{+} 6^{+}$and $\mathrm{CD}_{163}{ }^{+}$macrophages correlated with higher histological activity and fibrosis degrees in CHB patients [22, 44], whereas the causative role of macrophages in the development of HBV-related fibrosis has not been elucidated. To determine the role of HBeAg in the pathogenesis of HBV-related fibrosis, we used serum-free CM to stimulate HSCs, since serum contains growth factors and cytokines which may mask potential effects produced by macrophage-derived mediators on hepatic stellate cells [45]. We found a macrophage-dependent way induced by HBeAg to enhance the proliferation, contraction, and motility of HSCs. Consistent with findings in vivo, $\mathrm{HBeAg}$ represent a mediator of perpetual fibrogenesis, which is characterized by promoting the activation of HSCs, thereby exacerbating hepatic fibrosis. On the contrary, HBeAg alone cannot activate HSCs directly, even though HSCs do express TLR-2. This phenomenon could be ascribed to the extremely low expression of TLR-2 in HSCs (Table 3 and Additional file 1: Table S1). Moreover, the expression of TLR-2 in HSCs remained almost unchanged after being treated with HBeAg. Overall, HSCs and macrophages may play different roles in recognizing HBeAg, and the activation of HSCs induced by HBeAg requires the help of macrophages. Furthermore, we explored signal pathways responsible for these phenotypes. The Smad-dependent TGF- $\beta$ signaling pathway is generally considered to be the most effective fibrogenic pathway [15], in which signal transducing into the nucleus is mediated by phosphorylated receptor-activated Smads. Besides, many studies also identified TGF- $\beta$ exerts its actions via crosstalk with other signal pathways in a Smad- independent way, such as mitogen-activated protein kinase (MAPK), mammalian target of rapamycin (mTOR), phosphatidylinositol-3-kinase/AKT, and Rho GTPase pathways [46]. In this study, phenotypes of activated HSCs induced by HBeAg were often regulated by multiple pathways. The Smad-dependent TGF- $\beta$ signaling pathway is responsible for the proliferation and contraction of stellate cells, while PI3K-AKT-mTOR and p38 MAPK pathways may play a more vital role in the motility of HSCs. These data demonstrate that the activation of HSCs may be regulated through both Smaddependent and Smad-independent pathways, and further study should verify this conclusion with Smad2 and Smad3 knockout models. Except for TGF- $\beta$, various growth factors, cytokines, and chemokines, such as IL-6, TNF- $\alpha$, IL-1, PDGF, and CCL2, may also serve as messengers released from macrophages to regulate phenotypes of HSCs. Therefore, this specific crosstalk between macrophages and HSCs via these soluble proteins can be an aspect of further research.

Clinically, the progression of hepatic fibrosis caused by continuous inflammation response is an important factor of poor prognosis in $\mathrm{CHB}$ patients. $\mathrm{HBeAg}$ status has usually been identified as a significant serum marker to differentiate the natural history stage of CHB. Currently, it remains controversial with respect to the association between the HBeAg level and pathological fibrosis/inflammation degrees. In this study, we demonstrated that the $\mathrm{HBeAg}^{+}$status was related to higher inflammation or fibrotic degrees in CHB patients which was in accordance with previous studies [47-49]. Notably, the average age of recruited CHB patients is 54 years old, so we can exclude the vast majority of patients with immune tolerance who are always less than 30 years and characterized with $\mathrm{HBeAg}$ positivity but no significant immune response to the virus [50]. Moreover, a more close relationship was observed between $\mathrm{HBeAg}$ status and mild hepatic inflammation grades $(G \geq 1)$; thus, we surmised $\mathrm{HBeAg}$ may play a more important role in inducing the early inflammation response. However, other HBVrelated components as mentioned above may lead to the persistent inflammatory response. Even though a few studies have established $\mathrm{HBeAg}^{+}$status was independently associated with hepatic significant fibrosis [47], we further revealed that the concentration of serum $\mathrm{HBeAg}$ was increased with CD68 and $\alpha$-SMA-positive areas in $\mathrm{HBeAg}^{+}$patients. Therefore, the clinical data verified our findings that $\mathrm{HBeAg}$ promoted hepatic fibrosis via a macrophage-dependent manner.

In summary, our results have indicated that $\mathrm{HBeAg}$ mediated the innate immune response induced by macrophages through affecting the expression of TLRs and signal pathway activation. Moreover, we validated that TLR-2 was the direct binding receptor of HBeAg, and 


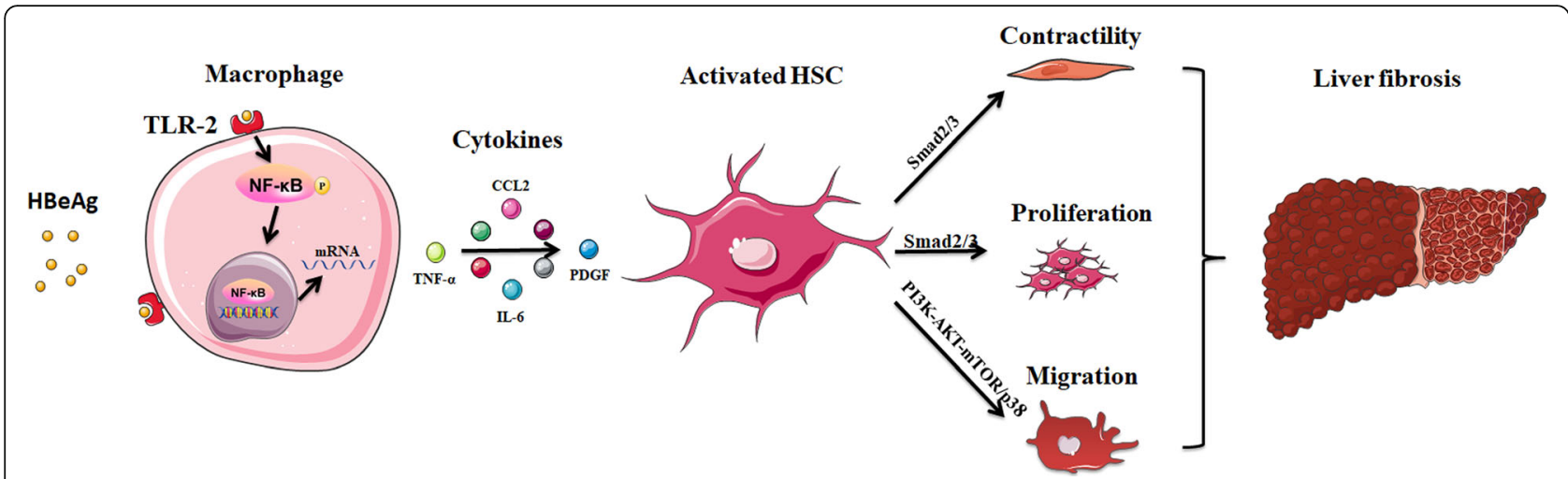

Fig. 7 Schematic diagram of HBeAg-mediated inflammatory functions of macrophages via TLR-2 contributing to hepatic fibrosis through stellate cell activation

C-terminal peptide (122-143 aa.) of core domain in $\mathrm{HBeAg}$ was critical for macrophage activation. Furthermore, HBeAg promoted the proliferation, contraction, and motility of HSCs in a macrophage-dependent manner. Mechanically, PI3K-AKT-mTOR and p38 MAPK signal pathway contributed to the motility of HSCs, while the Smad-dependent TGF- $\beta$ signal pathway promoted their proliferation and contraction. Additionally, soluble factors, such as CCL2, CCL5, CXCL10, and TNF- $\alpha$ may be responsible for these above phenotypes. In vivo, we further verified that $\mathrm{HBeAg}$ may play a more important role in the early inflammation response and promote the progression of hepatic fibrosis. Taken together, we unveiled a novel interaction between HBV infection and innate immune response via TLRs and further expanded the understanding of $\mathrm{HBV}$-induced hepatic fibrogenesis mechanism (Fig. 7).

\section{Conclusions}

HBeAg activated macrophages via the TLR-2/NF- $\kappa B$ signal pathway, and further exacerbated hepatic fibrosis by facilitating motility, proliferation, and contraction of HSCs with the help of macrophages.

\section{Abbreviations}

AHB: Acute hepatitis B; ANOVA: One-way analysis of variance; ArD: Argininerich domain; CCK-8: Cell Counting Kit-8; CHB: Chronic hepatitis B;

CM: Conditioned medium; CM-C: Conditioned medium collected from control; CM-E: Conditioned medium collected from activated macrophages by HBeAg; Co-IP: Co-immunoprecipitation; ECM: Extracellular matrix; ELISA: Enzyme-linked immunosorbent assay; EVs: Esophageal varices; HBCAg: Hepatitis B core antigen; HBcrAg: Hepatitis B core-related antigen; HBeAg: Hepatitis B e antigen; HBsAg: Hepatitis B surface antigen; HBV: Hepatitis B viruses; HCC: Hepatocellular carcinoma; HSC: Hepatic stellate cell; IEDB: Immune epitope database; OD: Optical density; PRR: Pattern recognition receptor; qRT-PCR: Quantitative real-time PCR; TLR: Toll-like receptor

\section{Supplementary Information}

The online version contains supplementary material available at https://doi. org/10.1186/s12916-021-02085-3.
Additional file 1. The expression of TLR-2 in $L X-2$ cells.

\section{Acknowledgements}

Not applicable.

\section{Authors' contributions}

QJ, ZQ, and XX designed, performed the research, analyzed the data, and wrote the paper. XX and LH developed the methods. XX, LC, SX, YZ, SS, and TM performed the experiments and analyzed the data. BH and QC helped to design the research, analyzed the data, and reviewed the manuscript. All authors contributed to writing the manuscript. All authors read and approved the final manuscript.

\section{Funding}

This work was supported in part by grants from the National Natural Science Foundation of China (81770607, 81772626, 81600469, 81570551), the Major Special Plan of Science and Technology of Shandong Province

(2015ZDXX0802A01), the Clinical Medical Science and Technology Innovation Program (202019094), and WBE Liver Fibrosis Foundation (CFHPC2021011).

Availability of data and materials

The data that support the findings of this study are available from the corresponding author upon reasonable request.

\section{Declarations}

Ethics approval and consent to participate

Informed consents were obtained from each of the patients/guardians by verbal/written before being included in this study, and this study was approved by the Ethics Committee of Shandong Provincial Hospital Affiliated to Shandong First Medical University. Institutional Review Board (IRB) number is LCYJ: NO. 2018-037.

Competing interests

The authors declare that they have no competing interests.

\section{Author details}

${ }^{1}$ Shandong Provincial Hospital Affiliated to Shandong First Medical University, Jinan, Shandong 250021, People's Republic of China. ${ }^{2}$ Shandong Provincial Hospital, Cheeloo College of Medicine, Shandong University, Jinan, Shandong 250021, People's Republic of China. 'Shandong Provincial Engineering and Technological Research Center for Liver Diseases Prevention and Control, Jinan, Shandong 250021, People's Republic of China. ${ }^{4}$ The First Affiliated Hospital of Xinjiang Medical University, Urumqi, Xinjiang 830054, People's Republic of China. 


\section{Received: 31 March 2021 Accepted: 3 August 2021}

Published online: 15 October 2021

\section{References}

1. World Health Organization. Global hepatitis report, 2017. 2017. https://apps. who.int/iris/handle/10665/255016.

2. Stanaway JD, Flaxman AD, Naghavi M, Fitzmaurice C, Vos T, Abubakar I, et al. The global burden of viral hepatitis from 1990 to 2013: findings from the global burden disease study 2013. Lancet. 2016;388(10049):1081-8. https://doi.org/10.1016/S0140-6736(16)30579-7.

3. Yuen MF, Chen DS, Dusheiko GM, Janssen HLA, Lau DTY, Locarnini SA, et al, Hepatitis B virus infection. Nat Rev Dis Primers. 2018;7(4):18035. https://doi. org/10.1038/nrdp.2018.35.

4. Hou X, Hao X, Zheng M, Xu C, Wang J, Zhou R, et al. CD205-TLR9-IL-12 axis contributes to $\mathrm{CpG}$-induced oversensitive liver injury in $\mathrm{HBsAg}$ transgenic mice by promoting the interaction of NKT cells with Kupffer cells. Cell Mol Immunol. 2017;14(8):675-84. https://doi.org/10.1038/cmi.2015.111.

5. Cooper A, Tal G, Lider O, Shaul Y. Cytokine induction by the hepatitis B virus capsid in macrophages is facilitated by membrane heparan sulfate and involves TLR2. J Immunol. 2005;175(5):3165-76. https://doi.org/10.4049/ jimmunol.175.5.3165

6. Levrero M, Zucman-Rossi J. Mechanisms of HBV-induced hepatocellular carcinoma. J Hepatol. 2016;64(1 Suppl):S84-S101. https://doi.org/10.1016/j. jhep.2016.02.021

7. Kramvis A, Kostaki EG, Hatzakis A, Paraskevis D. Immunomodulatory function of HBeAg related to short-sighted evolution, transmissibility, and clinical manifestation of hepatitis B virus. Front Microbiol. 2018;9:2521. https://doi. org/10.3389/fmicb.2018.02521.

8. Hösel M, Quasdorff M, Wiegmann K, Webb D, Zedler U, Broxtermann M, et al. Not interferon, but interleukin-6 controls early gene expression in hepatitis B virus infection. Hepatology. 2009;50(6):1773-82. https://doi.org/1 $0.1002 /$ hep. 23226

9. Wu J, Meng Z, Jiang M, Pei R, Trippler M, Broering R, et al. Hepatitis B virus suppresses toll-like receptor-mediated innate immune responses in murine parenchymal and nonparenchymal liver cells. Hepatology. 2009;49(4):113240. https://doi.org/10.1002/hep.22751.

10. Wang W, Bian H, Li F, Li X, Zhang D, Sun S, et al. HBeAg induces the expression of macrophage miR-155 to accelerate liver injury via promoting production of inflammatory cytokines. Cell Mol Life Sci. 2018;75(14):2627-41. https://doi.org/10.1007/s00018-018-2753-8

11. Takeuchi $O$, Akira S. Pattern recognition receptors and inflammation. Cell. 2010;140(6):805-20. https://doi.org/10.1016/j.cell.2010.01.022.

12. Chang S, Dolganiuc A, Szabo G. Toll-like receptors 1 and 6 are involved in TLR2-mediated macrophage activation by hepatitis C virus core and NS3 proteins. J Leukoc Biol. 2007;82(3):479-87. https://doi.org/10.1189/jlb.0207128.

13. Lin YL, Hu YC, Liang CC, Lin SY, Liang YC, Yuan HP, et al. Enterovirus-71 virus-like particles induce the activation and maturation of human monocyte-derived dendritic cells through TLR4 signaling. PLoS One. 2014; 9(10):e111496. https://doi.org/10.1371/journal.pone.0111496.

14. Wang L, Feng $Y$, Xie X, Wu H, Su XN, Qi J, et al. Neuropilin-1 aggravates liver cirrhosis by promoting angiogenesis via VEGFR2-dependent PI3K/Akt pathway in hepatic sinusoidal endothelial cells. EbioMedicine. 2019;43:52536. https://doi.org/10.1016/j.ebiom.2019.04.050.

15. Tsuchida T, Friedman SL. Mechanisms of hepatic stellate cell activation. Nat Rev Gastroenterol Hepatol. 2017;14(7):397-411. https://doi.org/10.1038/nrga stro.2017.38

16. Matsuda M, Seki E. Hepatic stellate cell-macrophage crosstalk in liver fibrosis and carcinogenesis. Semin Liver Dis. 2020;40(3):307-20. https://doi.org/10.1 055/s-0040-1708876.

17. European Association for the Study of the Liver. Electronic address: easloffice@easloffice.eu. EASL 2017 Clinical Practice Guidelines on the management of hepatitis B virus infection. J Hepatol. 2017;67(2):370-98. https://doi.org/10.1016/j.jhep.2017.03.021.

18. Poordad FF. Presentation and complications associated with cirrhosis of the liver. Curr Med Res Opin. 2015;31(5):925-37. https://doi.org/10.1185/03 007995.2015.1021905.

19. Mederacke I, Dapito DH, Affò S, Uchinami H, Schwabe RF. High-yield and high-purity isolation of hepatic stellate cells from normal and fibrotic mouse livers. Nat Protoc. 2015;10(2):305-15. https://doi.org/10.1038/nprot.2015.017.

20. The French METAVIR Cooperative Study Group. Intra-observer and interobserver variations in liver biopsy interpretation in patients with chronic hepatitis C. Hepatology. 1994;20(1 Pt 1):15-20. https://doi.org/10.1002/hep.1 840200104.

21. Bedossa P, Poynard T. An algorithm for the grading of activity in chronic hepatitis C: the METAVIR Cooperative Study Group. Hepatology. 1996;24(2): 289-93. https://doi.org/10.1002/hep.510240201.

22. Zhang JY, Zou ZS, Huang A, Zhang Z, Fu JL, Xu XS, et al. Hyper-activated pro-inflammatory CD16 monocytes correlate with the severity of liver injury and fibrosis in patients with chronic hepatitis B. PLoS One. 2011;6(3):e17484. https://doi.org/10.1371/journal.pone.0017484.

23. Leng J, Huang F, Hai Y, Tian H, Liu W, Fang Y, et al. Amelioration of nonalcoholic steatohepatitis by Qushi Huayu decoction is associated with inhibition of the intestinal mitogen-activated protein kinase pathway. Phytomedicine. 2020;66:153135. https://doi.org/10.1016/j.phymed.2019.153135.

24. Sharmin R, Islam AB. A highly conserved WDYPKCDRA epitope in the RNA directed RNA polymerase of human coronaviruses can be used as epitopebased universal vaccine design. BMC Bioinformatics. 2014;15(1):161. https:// doi.org/10.1186/1471-2105-15-161.

25. Bian H, Li F, Wang W, Zhao Q, Gao S, Ma J, et al. MAPK/p38 regulation of cytoskeleton rearrangement accelerates induction of macrophage activation by TLR4, but not TLR3. Int J Mol Med. 2017;40(5):1495-503. https://doi.org/1 0.3892/ijmm.2017.3143.

26. Manigold T, Böcker U, Chen J, Gundt J, Traber P, Singer MV, et al. Hepatitis B core antigen is a potent inductor of interleukin-18 in peripheral blood mononuclear cells of healthy controls and patients with hepatitis $B$ infection. J Med Virol. 2003;71(1):31-40. https://doi.org/10.1002/jmv.10445.

27. Iredale JP. Models of liver fibrosis: exploring the dynamic nature of inflammation and repair in a solid organ. J Clin Invest. 2007;117(3):539-48. https://doi.org/10.1172/JCl30542.

28. Marra F, Tacke F. Roles for chemokines in liver disease. Gastroenterology. 2014;147(3):577-594.e1.

29. Faure-Dupuy S, Durantel D, Lucifora J. Liver macrophages: friend or foe during hepatitis B infection? Liver Int. 2018;38(10):1718-29. https://doi.org/1 $0.1111 /$ liv.13884

30. Duffield JS, Forbes SJ, Constandinou CM, Clay S, Partolina M, Vuthoori S, et al. Selective depletion of macrophages reveals distinct, opposing roles during liver injury and repair. J Clin Invest. 2005;115(1):56-65. https://doi. org/10.1172/JCl200522675.

31. Boltjes A, Movita D, Boonstra A, Woltman AM. The role of Kupffer cells in hepatitis B and hepatitis C virus infections. J Hepatol. 2014;61(3):660-71. https://doi.org/10.1016/j.jhep.2014.04.026.

32. Vanlandschoot $P$, Van Houtte F, Roobrouck A, Farhoudi A, Stelter F, Peterson $\mathrm{DL}$, et al. LPS-binding protein and CD14-dependent attachment of hepatitis B surface antigen to monocytes is determined by the phospholipid moiety of the particles. J Gen Virol. 2002;83(Pt 9):2279-89. https://doi.org/10.1099/ 0022-1317-83-9-2279.

33. Wright TL, Roll FJ, Jones AL, Weisiger RA. Uptake and metabolism of polymerized albumin by rat liver. Role of the scavenger receptor. Gastroenterology. 1988;94(2):443-52. https://doi.org/10.1016/00165085(88)90435-0.

34. Op den Brouw ML, Binda RS, Geijtenbeek TB, Janssen HL, Woltman AM. The mannose receptor acts as hepatitis B virus surface antigen receptor mediating interaction with intrahepatic dendritic cells. Virology. 2009;393(1): 84-90. https://doi.org/10.1016/j.virol.2009.07.015.

35. Yang $C Y$, Kuo TH, Ting LP. Human hepatitis $B$ viral e antigen interacts with cellular interleukin-1 receptor accessory protein and triggers interleukin-1 response. J Biol Chem. 2006;281(45):34525-36. https://doi.org/10.1074/jbc.M510981200.

36. Werling D, Jann OC, Offord V, Glass EJ, Coffey TJ. Variation matters: TLR structure and species-specific pathogen recognition. Trends Immunol. 2009; 30(3):124-30. https://doi.org/10.1016/j.it.2008.12.001.

37. Vaure C, Liu Y. A comparative review of toll-like receptor 4 expression and functionality in different animal species. Front Immunol. 2014;5:316. https:// doi.org/10.3389/fimmu.2014.00316.

38. Hamonic G, Pasternak JA, Wilson HL. Recognizing conserved non-canonical localization patterns of toll-like receptors in tissues and across species. Cell Tissue Res. 2018;372(1):1-11. https://doi.org/10.1007/s00441-017-2767-9.

39. Isogawa M, Robek MD, Furuichi $Y$, Chisari FV. Toll-like receptor signaling inhibits hepatitis B virus replication in vivo. J Virol. 2005;79(11):7269-72. https://doi.org/10.1128/JVI.79.11.7269-7272.2005.

40. Xu L, Yin W, Sun R, Wei H, Tian Z. Kupffer cell-derived IL-10 plays a key role in maintaining humoral immune tolerance in hepatitis B virus-persistent mice. Hepatology. 2014;59(2):443-52. https://doi.org/10.1002/hep.26668. 
41. Dunn C, Peppa D, Khanna P, Nebbia G, Jones M, Brendish N, et al. Temporal analysis of early immune responses in patients with acute hepatitis $B$ virus infection. Gastroenterology. 2009;137(4):1289-300.

42. Zhang Z, Trippler M, Real Cl, Werner M, Luo X, Schefczyk S, et al. Hepatitis B virus particles activate Toll-like receptor 2 signaling initially upon infection of primary human hepatocytes. Hepatology. 2020;72(3):829-44.

43. Lang T, Lo C, Skinner N, Locarnini S, Visvanathan K, Mansell A. The hepatitis B e antigen (HBeAg) targets and suppresses activation of the toll-like receptor signaling pathway. J Hepatol. 2011;55(4):762-9. https://doi.org/10.1016/j.jhep.2010.12.042.

44. Dultz G, Gerber L, Farnik H, Berger A, Vermehren J, Pleli T, et al. Soluble CD163 is an indicator of liver inflammation and fibrosis in patients chronically infected with the hepatitis B virus. J Viral Hepat. 2015;22(4):42732. https://doi.org/10.1111/jvh.12309.

45. Nieto N. Oxidative-stress and IL-6 mediate the fibrogenic effects of Kupffer cells on stellate cells. Hepatology. 2006;44(6):1487-501. https://doi.org/10.1 002/hep.21427.

46. Dewidar B, Meyer C, Dooley S, Meindl-Beinker AN. TGF- $\beta$ in hepatic stellate cell activation and liver fibrogenesis-updated 2019. Cells. 2019;8(11):1419. https://doi.org/10.3390/cells8111419.

47. Lai M, Hyatt BJ, Nasser I, Curry M, Afdhal NH. The clinical significance of persistently normal ALT in chronic hepatitis B infection. J Hepatol. 2007; 47(6):760-7. https://doi.org/10.1016/j.jhep.2007.07.022.

48. Kumar M, Sarin SK, Hissar S, Pande C, Sakhuja P, Sharma BC, et al. Virologic and histologic features of chronic hepatitis B virus-infected asymptomatic patients with persistently normal ALT. Gastroenterology. 2008;134(5):137684. https://doi.org/10.1053/j.gastro.2008.02.075.

49. Seto WK, Lai CL, Ip PP, Fung J, Wong DK, Yuen JC, et al. A large population histology study showing the lack of association between ALT elevation and significant fibrosis in chronic hepatitis B. PLoS One. 2012;7(2):e32622. https:// doi.org/10.1371/journal.pone.0032622.

50. Vlachogiannakos J, Papatheodoridis GV. HBV: Do I treat my immunotolerant patients? Liver Int. 2016;36(Suppl 1):93-9. https://doi.org/10.1111/liv.12996.

\section{Publisher's Note}

Springer Nature remains neutral with regard to jurisdictional claims in published maps and institutional affiliations.

Ready to submit your research? Choose BMC and benefit from:

- fast, convenient online submission

- thorough peer review by experienced researchers in your field

- rapid publication on acceptance

- support for research data, including large and complex data types

- gold Open Access which fosters wider collaboration and increased citations

- maximum visibility for your research: over $100 \mathrm{M}$ website views per year

At $\mathrm{BMC}$, research is always in progress.

Learn more biomedcentral.com/submissions 